This document is confidential and is proprietary to the American Chemical Society and its authors. Do not copy or disclose without written permission. If you have received this item in error, notify the sender and delete all copies.

\title{
Homogeneous Catalysis Under Ultra-Dilute Conditions: TAML/NaClO Oxidation of Persistent Metaldehyde
}

\begin{tabular}{|r|l|}
\hline Journal: & Journal of the American Chemical Society \\
\hline Manuscript ID & ja-2016-11145f.R1 \\
\hline Manuscript Type: & Article \\
\hline Complete List of Authors: & $\begin{array}{l}\text { Tang, Liang; Carnegie Mellon University, Department of Chemistry } \\
\text { DeNardo, Matthew; Carnegie Mellon University - Chemistry, } \\
\text { Schuler, Christopher; Institute for Green Science, Chemistry } \\
\text { Mills, Matthew; Carnegie Mellon University, Chemistry } \\
\text { Gayathri, Chakicherla; Carnegie Mellon University, Chemistry } \\
\text { Gil, Roberto; Carnegie Mellon University, Chemistry } \\
\text { Kanda, Rakesh; Brunel University London, Institute of Environment, Health } \\
\text { and Societies } \\
\text { Collins, Terrence; Carnegie Mellon University, Chemistry }\end{array}$ \\
\hline
\end{tabular}

SCHOLARONE

Manuscripts 
$\log \left(k_{\mathrm{II}} \times k_{\mathrm{i}}^{-1} / \mathrm{M}^{-1}\right)$ for any suitable catalyst $\%$ Conversion

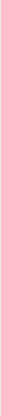




\title{
Homogeneous Catalysis Under Ultra-Dilute Conditions: TAML/NaClO Oxidation of Persistent Metaldehyde
}

\author{
Liang L. Tang, ${ }^{\dagger}$ Matthew A. DeNardo, ${ }^{\dagger}$ Christopher J. Schuler, ${ }^{\dagger}$ Matthew R. Mills, ${ }^{\dagger}$ Chakicherla Ga- \\ yathri, ${ }^{\dagger}$ Roberto R. Gil,$^{\dagger}$ Rakesh Kanda, ${ }^{\dagger}$ and Terrence J. Collins, ${ }^{*} \dagger$ \\ ${ }^{\dagger}$ Institute for Green Science, Department of Chemistry, Carnegie Mellon University, 4400 Fifth Avenue, Pittsburgh, Penn- \\ sylvania 15213, United States \\ ${ }^{\sharp}$ Institute for the Environment, Brunel University, Halsbury Building (130), Kingston Lane, Uxbridge, Middlesex, UB8 3PH, \\ United Kingdom
}

\begin{abstract}
TAML activators enable homogenous oxidation catalysis where the catalyst and substrate (S) are ultra-dilute (pMlow $\mu \mathrm{M}$ ) and the oxidant is very dilute (high $\mathrm{nM}$-low $\mathrm{mM}$ ). Water contamination by exceptionally persistent micropollutants (MPs), including metaldehyde (Met), provides an ideal space for determining the characteristics and utilitarian limits of this ultradilute catalysis. The low MP concentrations decrease throughout catalysis with $\mathrm{S}$ oxidation $\left(k_{\mathrm{II}}\right)$ and catalyst inactivation $\left(k_{\mathrm{i}}\right)$ competing for the active catalyst. The percentage of substrate converted $(\% \mathrm{Cvn})$ can be increased by discovering methods to increase $k_{\mathrm{II}} / k_{\mathrm{i}}$. Here we show that $\mathrm{NaClO}$ extends catalyst lifetime to increase the Met turnover number (TON) threefold compared with $\mathrm{H}_{2} \mathrm{O}_{2}$, highlighting the importance of oxidant choice as a design tool in TAML systems. Met oxidation studies ( $\mathrm{pH} 7, \mathrm{D}_{2} \mathrm{O}, 0.01 \mathrm{M}$ phosphate, $25^{\circ} \mathrm{C}$ ) monitored by ${ }^{1} \mathrm{H}$ NMR spectroscopy show benign acetic acid as the only significant product. Analysis of TAML/NaClO treated Met solutions employing successive identical catalyst doses revealed that the processes can be modeled by the recently published relationship between the initial and final $[\mathrm{S}]\left(\mathrm{S}_{0}\right.$ and $\mathrm{S}_{\infty}$, respectively), the initial [catalyst] (Fe $\left.\mathrm{Fot}_{\mathrm{Tot}}\right)$ and $k_{\mathrm{II}} / k_{\mathrm{i}}$. Consequently, this study establishes that $\Delta \mathrm{S}$ is proportional to $\mathrm{S}_{0}$ and that the \%Cvn is conserved across all catalyst doses in multicatalyst-dose processes because the rate of the $k_{\mathrm{II}}$ process depends on [S] while that of the $k_{\mathrm{i}}$ process does not. A general tool for determining the $\mathrm{Fe}_{\mathrm{Tot}}$ required to effect a desired \%Cvn is presented. Examination of the dependence of TON on $k_{\mathrm{II}} / k_{\mathrm{i}}$ and $\mathrm{Fe}_{\mathrm{Tot}}$ at a fixed $\mathrm{S}_{0}$ indicates that for any TAML process employing $\mathrm{Fe}_{\mathrm{Tot}}<1 \times 10^{-6} \mathrm{M}$, small catalyst doses are not more efficient than one large dose.
\end{abstract}

\section{Introduction}

The development of homogeneous oxidation catalysis that is effective under ultra-dilute conditions promises to enable a new branch of chemistry with implications for sustainability. For example, micropollutants (MPs) produce adverse effects in aquatic organisms at environmentally relevant low parts per billion (ppb) to low parts per trillion (ppt) concentrations. ${ }^{1-2}$ Currently, Switzerland is installing end-of-plant ozone and activated carbon (AC) technologies for reducing MP concentrations in municipal wastewater, but both are expensive. ${ }^{3}$ TAML catalyzed peroxide oxidations of MPs function so well under ultra-dilute conditions (low ppb, low nM) that novel and cheaper processes for the removal of MPs are now within reach. ${ }^{4-12}$ TAML/ $\mathrm{H}_{2} \mathrm{O}_{2}$ has been shown to remove low $\mathrm{ppb}$ low ppt (low nM-low pM) concentrations of MPs of highest concern from London municipal wastewater with comparable technical performance to ozone and projected superior cost performance. ${ }^{13}$ Certain MPs are not effectively removed from water by ozone or AC. ${ }^{14}$ For example, metaldehyde (Met, Chart 1) is so persistent that very expensive advanced oxidation processes (e.g., $\mathrm{UV} / \mathrm{H}_{2} \mathrm{O}_{2}$ ) need to be applied when drinking water is unacceptably contaminated. ${ }^{15-17} \mathrm{~A}$ discussion of the challenges Met poses to water treatment and available removal methods has been published ${ }^{14}$ and a more thorough list of the available Met removal methods can be found in the
Chart 1. Structures of the $M$ I diastereomer of metaldehyde and TAML ${ }^{\mathrm{a}}$ compounds 1 .

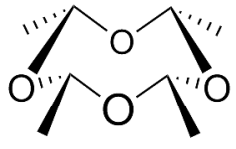

Metaldehyde (M I diastereomer)

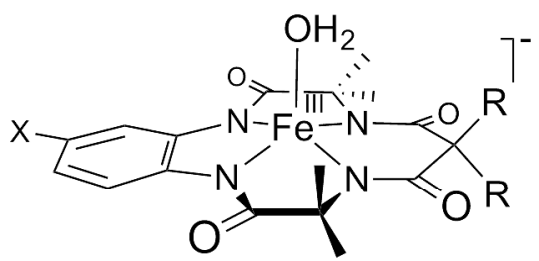

1a: $X=\mathrm{NO}_{2}, \mathrm{R}=\mathrm{F}$

1b: $X=H, R=M e$
${ }^{a}$ TAML is a registered trademark covering tetra-amido- $N$ macrocyclic ligand complexes. ${ }^{18}$

Supplementary Information of this work (Tables S1-3). Therefore, we have are exploring TAML catalysis of Met oxidation. Met oxidation exacts the most demanding performance of TAML/ $\mathrm{H}_{2} \mathrm{O}_{2}$ systems studied to date. ${ }^{14}$ We have shown that 1a/ $\mathrm{H}_{2} \mathrm{O}_{2}$ (Chart 1) is capable of oxidizing Met. However, in contrast with most MPs, both the $1 \mathbf{a} / \mathrm{H}_{2} \mathrm{O}_{2}$ rates of Met oxidation and the balance between these and the rates of catalyst inactivation were too unfavorable to promise a real-world solution. Therefore, we have identified Met as a boundary case, one for which effective oxidation will be either just possible or just not possible. By working to improve the technical performance in this extreme case, we have encountered a significant 
advantage resulting from changing the oxidant from $\mathrm{H}_{2} \mathrm{O}_{2}$ to hypochlorite. Hypochlorite is widely employed in US water disinfection processes ${ }^{1}$ where it is generated in situ from chlorine gas at a low cost. ${ }^{19}$ We have long known that TAML activators catalyze hypochlorite reactions. ${ }^{20} \mathrm{NaClO}$ activates TAML catalysts to give $\mathrm{Fe}^{\mathrm{V}}=\mathrm{O}$ complexes from $-40{ }^{\circ} \mathrm{C}^{21}$ to room temperature, ${ }^{22}$ highlighting a similarity with the most reactive intermediates in TAML/ $\mathrm{H}_{2} \mathrm{O}_{2}$ systems. ${ }^{23}$

Here we examine the 1a $(0.4-6.4 \mu \mathrm{M})$ catalyzed degradation of Met $(0.33 \mathrm{mM})$ by $\mathrm{NaClO}(0.008-0.02 \mathrm{M})$ at $25^{\circ} \mathrm{C}$ and $\mathrm{pH}$ 7 (0.01 M phosphate) in $\mathrm{D}_{2} \mathrm{O}$. The shift from $1 \mathbf{a} / \mathrm{H}_{2} \mathrm{O}_{2}$ to $\mathbf{1 a} / \mathrm{NaClO}$ results in a threefold improvement in process technical performance, establishing that oxidant choice is an important process design parameter for these systems. Effective oxidation of the very resistant Met required the addition of multiple catalyst doses over which a consistent relationship was found between [Met $]_{0}$ (initial [Met]) and the $\Delta[\mathrm{Met}]$ which held for all 18 sequential catalyst treatments. These results have served as an entry point for augmenting the mathematical logic which models TAML catalysis and for developing a 3-D map that will typically allow prediction of the percent conversion $(\% \mathrm{Cvn})$ of any concentration of a substrate by any TAML catalyst under broadly specified conditions. The map holds considerable promise as a tool for TAML-based water purification. It predicts the amount of catalyst needed to achieve a targeted substrate removal and identifies boundary pollutants that are exceptionally difficult to treat with the current set of TAML catalysts. Finally, we show that when [TAML] $<1 \times 10^{-6} \mathrm{M}$, the efficiency of oxidation of easily oxidized pollutants is inversely related to [TAML] because the substrate undergoes dilution, while in the transformation of boundary pollutants TON is independent of [TAML].

\section{Materials and methods}

Materials. All reagents, components of buffered solutions, and solvents were of at least ACS reagent grade and were used as received. Met (Acros, 99\%) was recrystallized in ethanol ${ }^{24}$ and stored at $4{ }^{\circ} \mathrm{C}$. Since three isomers of Met, each having a distinct infrared (IR) spectrum are known, the IR spectrum of the recrystallized sample was recorded (Fig. S1). The spectrum is nearly identical to that previously assigned ${ }^{25}$ to the metaldehyde I (M I) diastereomer, the most abundant form of Met, the structure of which was previously determined by X-ray crystallography (Chart 1). ${ }^{26}$ Met stock solutions $(0.3 \mathrm{mM})$ were prepared by sonicating the appropriate amount of Met in buffered $\mathrm{D}_{2} \mathrm{O}(99.9 \%$, Cambridge Isotope Laboratories, Inc.) at room temperature for $3 \mathrm{~h}$. Buffers of the desired $\mathrm{pHs}(6.2-7.0)$ were prepared with $0.01 \mathrm{M}$ phosphate and monitored by an Accumet $\mathrm{AB} 15 \mathrm{pH}$ meter at room temperature. A solution of $\mathrm{DCl}$ in $\mathrm{D}_{2} \mathrm{O}$ was added to adjust the reaction mixture $\mathrm{pH}$ to 7 after $\mathrm{NaClO}$ addition. The reported values are the uncorrected $\mathrm{pH}$ meter readings. TAML activator 1a was provided by GreenOx Catalysts Inc. Stock solutions of $1 \mathrm{a}\left(2 \times 10^{-4} \mathrm{M}\right)$ were prepared in $\mathrm{D}_{2} \mathrm{O}$ and stored at $4{ }^{\circ} \mathrm{C} . \mathrm{H}_{2} \mathrm{O}_{2}$ and $\mathrm{NaClO}$ solutions were standardized daily by measuring the absorbances at $230 \mathrm{~nm}\left(\varepsilon=72.4 \mathrm{M}^{-1} \mathrm{~cm}^{-1}\right)^{27}$ and $293 \mathrm{~nm}\left(\varepsilon=350 \mathrm{M}^{-}\right.$ $\left.{ }^{1} \mathrm{~cm}^{-1}\right),{ }^{28}$ respectively. The specified [ $\left.\mathrm{NaClO}\right]$ values are those of the added reagent - at $\mathrm{pH} 7 \mathrm{NaClO}$ is ca $70 \% \mathrm{HOCl}$.

Instrumental. IR measurements were performed on a Mattson ATI Affinity 60 AR FTIR spectrometer using KBr pellet. UVVis measurements were performed on an Agilent $8453 \mathrm{UV}$ Vis spectrophotometer equipped with an 8-cell transporter and thermostatic temperature controller. Solution temperatures were maintained at $25^{\circ} \mathrm{C}$ in capped quartz cuvettes $(1.0 \mathrm{~cm})$.

TAML catalysis of metaldehyde oxidation was followed by ${ }^{1} \mathrm{H}$ NMR. 1D ${ }^{1} \mathrm{H}$ spectra were recorded at $300 \mathrm{~K}$ on a Bruker Avance III 500 NMR spectrometer operating at $500.13 \mathrm{MHz}$. The water signal was suppressed using the presaturation experiment (zgpr) from the Bruker pulse programs library. Chemical shifts are reported in parts per million relative to TMSP (an internal standard for aqueous solutions, see Abbreviations). However, since TAML catalyzed oxidation of an internal standard could interfere with measurements, none was added. $^{14}$ Each sample was scanned 128 times over 16.5 minutes. The Bruker TopSpin 3.0 software was used to process the NMR data. The Met $\left(\mathrm{CH}_{3} \mathrm{CHO}\right)_{4}$ and acetic acid $\mathrm{C}_{3} \mathrm{COOH}$ absolute integrals were used for quantification. Each data point is the average of three measurements and the associated error is the standard deviation of the set.

\section{Results and discussion}

The choice of oxidant is a process design tool for advancing TAML catalyst lifetimes. To assess the relative performances of $1 \mathbf{a} / \mathrm{NaClO}$ and $1 \mathrm{a} / \mathrm{H}_{2} \mathrm{O}_{2},{ }^{1} \mathrm{H}$ NMR measurements were performed on Met solutions in $\mathrm{D}_{2} \mathrm{O}$ under identical conditions. As shown in Fig. 1A, the [Met] is unaffected by either $\mathrm{NaClO}$ or $\mathrm{H}_{2} \mathrm{O}_{2}$ alone. The $\mathrm{NaClO}$ kinetic trace shows that a single 1a dose giving a [1a] of $3.98 \times 10^{-7} \mathrm{M}$ effects a $14.4 \%$ conversion $(14.4 \% \mathrm{Cvn})$ as indicated by a reduction in the absolute integral of the $1.34 \mathrm{ppm} \mathrm{Met} \underline{\mathrm{CH}}_{3}$ signal over the approximate duration of catalysis of 80 hours (Table 1). For comparison, in the corresponding $1 \mathrm{a} / \mathrm{H}_{2} \mathrm{O}_{2}$ experiment, a $4.3 \% \mathrm{Cvn}$ is observed over the approximate duration of catalysis, which this time lasted only 10 hours. In both cases, the relationship between [Met] and time is initially linear allowing calculation of the initial oxidation rates $(v=\mathrm{d}[\mathrm{S}] / \mathrm{dt})$ by fitting a linear form. While the initial rates of Met consumption are identical, a turnover number (TON) of 106 is observed in the $\mathrm{NaClO}$ system compared with 32 in the $\mathrm{H}_{2} \mathrm{O}_{2}$ system, a three-fold improvement. These reaction features are also visible in the kinetic traces for acetic acid production (Fig. 1B), with ca. 5 times more acetic acid being produced by $1 \mathbf{a} / \mathrm{NaClO}$. Under these conditions $\mathbf{1 a} / \mathrm{H}_{2} \mathrm{O}_{2}$ generates an acetic acid:acetaldehyde product ratio of $3: 1$. The respective acetic acid and acetaldehyde rat $\mathrm{LD}_{50}$ values are 3,310 and $661 \mathrm{mg} \mathrm{kg}^{-1}$ suggesting that selectivity for acetic acid is desirable. ${ }^{29}$ The near exclusive production of acetic acid by $\mathbf{1 a} / \mathrm{NaClO}$ leads to an even more benign product mixture. Because chlorination of water containing organic matter generates hazardous disinfection byproducts (DBPs), including carcinogenic chloroform, ${ }^{30-}$ ${ }^{31}$ we have monitored for chloroform production-none was detected within the limits of the NMR technique. 

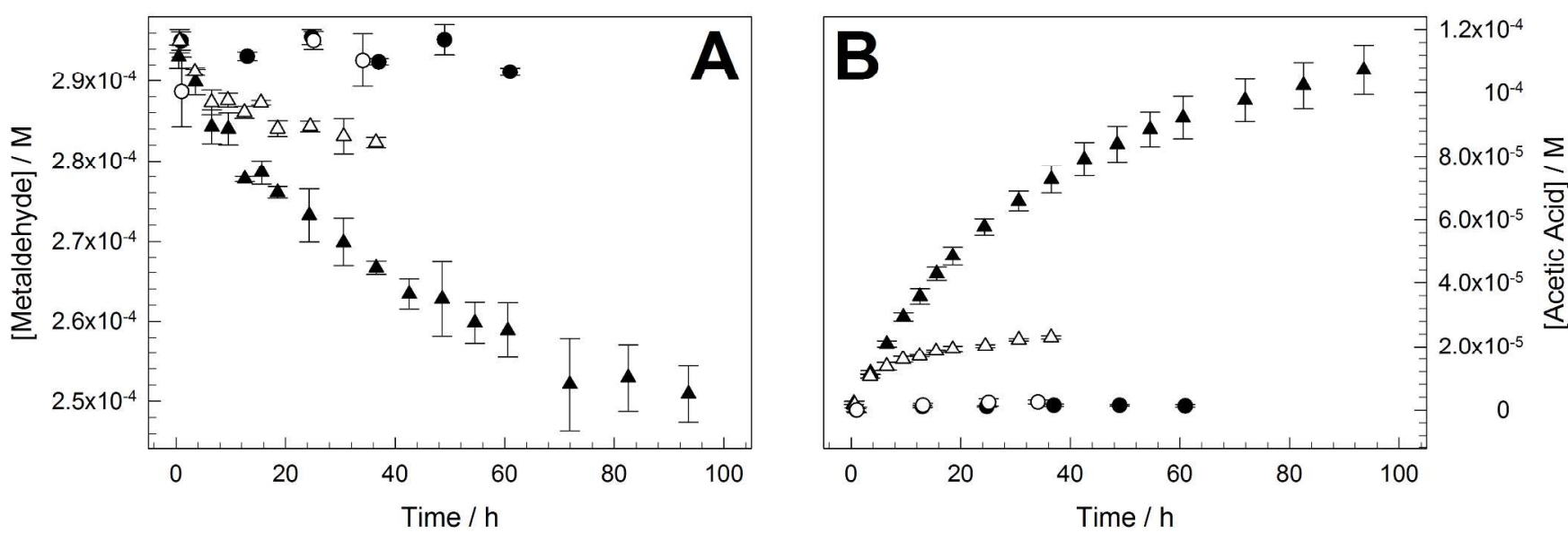

Figure 1. Oxidation of Met $\left(2.95 \times 10^{-4} \mathrm{M}\right)$ by $\mathrm{NaClO}\left(3.8 \times 10^{-3} \mathrm{M}, 13\right.$ eq $)$ or $\mathrm{H}_{2} \mathrm{O}_{2}\left(3.61 \times 10^{-3} \mathrm{M}, 12 \mathrm{eq}\right)$ at $\mathrm{pH}$ 7. Kinetic traces of (A): metaldehyde consumption and (B): acetic acid formation. Circles: metaldehyde plus oxidant control experiments $\left(\bullet \mathrm{NaClO}\right.$ and $\left.\circ \mathrm{H}_{2} \mathrm{O}_{2}\right)$. Triangles: 1a $\left(3.98 \times 10^{-7} \mathrm{M}\right)$ catalyzed oxidations $\left(\boldsymbol{\Delta} \mathrm{NaClO}\right.$ and $\left.\triangle \mathrm{H}_{2} \mathrm{O}_{2}\right)$. Conditions: $\mathrm{pH} 7 \mathrm{D}_{2} \mathrm{O}(0.01 \mathrm{M}$, phosphate), reactions were allowed to proceed at room temperature. Concentrations were calculated from the absolute integrals of the metaldehyde and acetic acid $\mathrm{CH}_{3}$ signals at 1.34 and $1.92 \mathrm{ppm}$, respectively. The initial ${ }^{1} \mathrm{H}$ NMR integrals for the trace amounts of acetic acid that formed on sonication of metaldehyde were subtracted from those of the total acetic acid.

Table 1. Comparison of $1 \mathrm{a} / \mathrm{NaClO}$ and $1 \mathrm{a} / \mathrm{H}_{2} \mathrm{O}_{2}$ systems in catalysis of metaldehyde degradation at $\mathrm{pH}$ 7. Conditions: [Met] $=2.95 \times 10^{-4} \mathrm{M},[1 \mathrm{a}]=3.98 \times 10^{-7} \mathrm{M},[\mathrm{NaClO}]=3.8 \times 10^{-3} \mathrm{M},\left[\mathrm{H}_{2} \mathrm{O}_{2}\right]=3.6 \times 10^{-3} \mathrm{M}$.

\begin{tabular}{cccccc}
\hline Oxidant & $v \times 10^{8} / \mathrm{M} \mathrm{min}^{-1 \mathrm{a}}$ & Removal $/ \%$ & Major Products & TON & Functioning Time \\
\hline $\mathrm{NaClO}$ & $2.4 \pm 0.4$ & $14.4 \pm 0.9$ & acetic acid & $106 \pm 6$ & $80 \mathrm{~h}$ \\
\hline $\mathrm{H}_{2} \mathrm{O}_{2}$ & $2.2 \pm 0.3$ & $4.3 \pm 0.7$ & $\begin{array}{c}\text { acetaldehyde and } \\
\text { acetic acid }\end{array}$ & $32 \pm 5$ & $10 \mathrm{~h}$
\end{tabular}

${ }^{\text {a }}$ The rate $(v)$ is calculated from the slope of the line of best fit to the first three [Met] measurements ( $v=\mathrm{d}[\mathrm{Met}] / \mathrm{dt}$ ).

The identical initial rates of Met oxidation observed for $\mathrm{NaClO}$ and $\mathrm{H}_{2} \mathrm{O}_{2}$ are informative. TAML catalysts function via the stoichiometric mechanism of Scheme 1 . The resting catalysts $\left(\mathrm{Fe}^{\mathrm{III}}\right)$ undergo activation by an oxidant $\left(\mathrm{Ox}, k_{\mathrm{I}}\right)$ to form active catalysts $(\mathrm{Ac})$ which then oxidize a substrate $(\mathrm{S})$ to give $\mathrm{Fe}^{\mathrm{III}}$ and product(s) $\left(k_{\mathrm{II}}\right)$ or undergo inactivation $\left(k_{\mathrm{i}}\right.$ or $k_{2 \mathrm{i}}$ ) - the reverse of catalyst activation, $k_{-\mathrm{I}}$, is kinetically negligible.

Scheme 1. General mechanism of TAML catalysis.

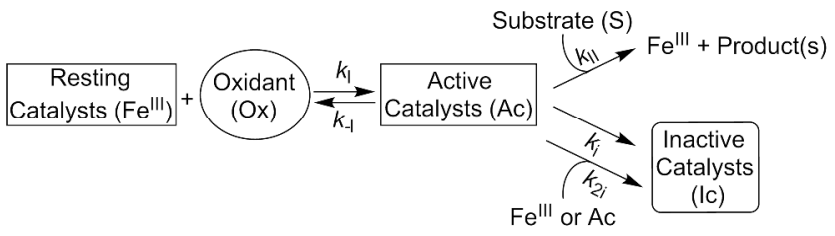

Equation 1 models the initial rate of substrate oxidation $\left(\mathrm{Fe}_{\mathrm{Tot}}\right.$ is the total concentration of catalyst). ${ }^{35}$ For particularly difficult to oxidize substrates, catalyst activation outpaces substrate oxidation $\left(k_{\mathrm{I}}[\mathrm{Ox}]>k_{\mathrm{II}}[\mathrm{S}]\right)$ and eq 1 simplifies to eq 2 .

$v=\frac{k_{\mathrm{I}} k_{\mathrm{II}}[\mathrm{Ox}][\mathrm{S}]}{k_{-\mathrm{I}}+k_{\mathrm{I}}[\mathrm{Ox}]+k_{\mathrm{II}}[\mathrm{S}]} \mathrm{Fe}_{\mathrm{Tot}}$

$v=k_{\mathrm{II}}[\mathrm{S}] \mathrm{Fe}_{\text {Tot }}$
Substrate oxidation and catalyst inactivation compete for Ac. Recently, we have developed eq $3,{ }^{32}$ a mathematical form that models the final result of this competition, $\mathrm{S}_{\infty}\left(\mathrm{S}_{0}\right.$ and $\mathrm{S}_{\infty}$ are the initial and final [S], respectively). Equation 3 applies only when there is an excess of the primary oxidant and substrate consumption is incomplete $\left(\mathrm{S}_{\infty}>0\right)$, i.e. conditions are set such that the catalyst is the limiting species and is completely inactivated before all of the substrate has been oxidized. These conditions were employed in the Met oxidation experiments described herein.

$\ln \frac{\mathrm{S}_{0}}{\mathrm{~S}_{\infty}}=\frac{k_{\text {II }}}{k_{\mathrm{i}}} \mathrm{Fe}_{\text {Tot }}$

For most TAML processes, $k_{\mathrm{I}}[\mathrm{Ox}]<k_{\mathrm{II}}[\mathrm{S}]$ and catalyst activation is rate determining. However, Met oxidation by Ac is extremely slow. Of tested TAML $/ \mathrm{H}_{2} \mathrm{O}_{2}$ processes, ${ }^{14}$ the 1a system is known to deliver the highest measurable $v$ and $\%$ Cvn. The eq 3 estimated $k_{\text {II }}$ value for $1 \mathbf{a} / \mathrm{H}_{2} \mathrm{O}_{2}$ is $120 \pm 30 \mathrm{M}^{-}$ ${ }^{1} \mathrm{~s}^{-1}$, ca. 340 times lower than the corresponding value for Orange II of $41,000 \pm 1,000 \mathrm{M}^{-1} \mathrm{~s}^{-1}$, noting of course that the Orange II $k_{\mathrm{II}}$ and $k_{\mathrm{i}}$ were measured in $\mathrm{H}_{2} \mathrm{O}$ while the Met data were recorded in $\mathrm{D}_{2} \mathrm{O}^{33}$ Given this value, the $1 \mathrm{a} / \mathrm{H}_{2} \mathrm{O}_{2}\left(\mathrm{D}_{2} \mathrm{O}\right)$ Met process exhibits the lowest $k_{\text {II }}$ (and \% Cvn, see later) at $\mathrm{pH}$ 7 of any MP oxidation studied to date. The eq 3 estimated $\mathbf{1 a} / \mathrm{H}_{2} \mathrm{O}_{2}\left(\mathrm{D}_{2} \mathrm{O}\right)$ Met $k_{\mathrm{II}}$ is comparable to the $1 \mathbf{a} / \mathrm{H}_{2} \mathrm{O}_{2}\left(\mathrm{D}_{2} \mathrm{O}\right) k_{\mathrm{I}}$ of $180 \pm 8 \mathrm{M}^{-1} \mathrm{~s}^{-1}$. Since $k_{\mathrm{I}} \sim k_{\mathrm{II}}$ for this Met system, and $\left[\mathrm{H}_{2} \mathrm{O}_{2}\right]>10 \times[\mathrm{Met}]$, the oxidation of this very difficult sub- 
strate by Ac is rate-determining and eq 2 applies. This is further supported by the similarity of the rates for both oxidants which also provides strong evidence for rate determining substrate oxidation by a common Ac. Noting again that acetaldehyde is observed in the $1 \mathbf{a} / \mathrm{H}_{2} \mathrm{O}_{2}\left(\mathrm{D}_{2} \mathrm{O}\right)$ study, it follows that the known oxidation of acetaldehyde by $\mathrm{NaClO}^{34}$ probably accounts for the virtual absence of acetaldehyde in the $\mathbf{1 a} / \mathrm{NaClO}$ product mixture. Since, as indicated by eq 3 , $\ln \mathrm{S}_{0} / \mathrm{S}_{\infty}$ is fixed by $k_{\mathrm{II}} \mathrm{Fe}^{\mathrm{III}}{ }_{\text {Tot }} / k_{\mathrm{i}}$, and both the $\mathrm{NaClO}$ and $\mathrm{H}_{2} \mathrm{O}_{2}$ processes share a common rate determining step with a common Ac, the $\mathrm{NaClO}$ performance advantage must derive from a decrease in $k_{\mathrm{i}}$ which is reflected in the greater reduction in [Met] and longer operating time. The $\mathbf{1 a} / \mathrm{NaClO} k_{\mathrm{i}}$ value matches that of $\mathbf{1 b} / \mathrm{H}_{2} \mathrm{O}_{2}{ }^{33}$ Since the 1a Ac oxidizes substrates ca. one order of magnitude faster than $\mathbf{1 b}$, this amounts to a $k_{\mathrm{II}} / k_{\mathrm{i}}$ gain of ca. one order of magnitude on going from the $1 \mathbf{b} / \mathrm{H}_{2} \mathrm{O}_{2}$ to $1 \mathrm{a} / \mathrm{NaClO}$ systems. Considering that $k_{\mathrm{II}}$ and $k_{\mathrm{i}}$ have been found to track linearly for all TAML catalysts, this gain in operational stability with preservation of oxidative activity is remarkable. ${ }^{33}$

The inactivation of TAML catalysts has been found to follow both intramolecular suicidal ${ }^{35-37}$ and intermolecular $\mathrm{H}_{2} \mathrm{O}_{2}$ dependent pathways ${ }^{36,38}$ which are unimolecular in catalyst. To minimize the performance reducing impacts of the latter in ultra-dilute catalysis, a low $\left[\mathrm{H}_{2} \mathrm{O}_{2}\right]$ is generally employed. In one case, a system in which $\mathrm{H}_{2} \mathrm{O}_{2}$ is generated enzymatically in situ has been devised. ${ }^{39}$ By using $\mathrm{NaClO}$, we have eliminated the $\mathrm{H}_{2} \mathrm{O}_{2}$-dependent catalyst inactivation pathways altogether. The TON increases by $70 \%$ on changing from $\mathrm{H}_{2} \mathrm{O}_{2}$ to $\mathrm{NaClO}$. The recently published $1 \mathrm{a} / \mathrm{H}_{2} \mathrm{O}_{2} k_{\mathrm{i}}^{33}$ of $(1.1 \pm 0.3) \times$ $10^{-3} \mathrm{~s}^{-1}$ is ca $70 \%$ greater than the eq 3 estimated $\mathrm{NaClO} k_{\mathrm{i}}$ value of $(3.0 \pm 0.8) \times 10^{-4} \mathrm{~s}^{-1}$. These comparisons indicate that in $\mathrm{D}_{2} \mathrm{O}$, at least $70 \%$ of the $k_{\mathrm{i}}$ processes are attributable to $\mathrm{H}_{2} \mathrm{O}_{2}$ dependent catalyst inactivation. The lifetime extension observed for the $\mathbf{1 a} / \mathrm{NaClO}$ catalysis further establishes the importance of understanding the nature of the $\mathrm{H}_{2} \mathrm{O}_{2}$ dependent inactivation pathway in TAML/ $\mathrm{H}_{2} \mathrm{O}_{2}$ catalysis.

Effects of different catalyst concentrations. The identical initial rates of $\mathbf{1 a} / \mathrm{H}_{2} \mathrm{O}_{2}$ and $\mathbf{1 a} / \mathrm{NaClO}$ Met consumption are slow (Table 1). The effect of [1a] on the oxidation was examined with the aim of increasing both $v$ and the $\%$ Cvn. Since the $\mathrm{H}_{2} \mathrm{O}_{2} \%$ Cvn with [1a] $=3.98 \times 10^{-7} \mathrm{M}$ was small, only higher [1a] experiments were performed in the $\mathrm{H}_{2} \mathrm{O}_{2}$ system (Fig. 1). Surprisingly, the anticipated increases in $v$ and $\% \mathrm{Cvn}$ with increasing [1a] to $1.66 \times 10^{-6} \mathrm{M}$ were not observed. Instead, the kinetic trace is largely indistinguishable from that of the control experiment (Figs. 2 and S5).

Kinetic traces of the oxidation of Met $\left(2.95 \times 10^{-4} \mathrm{M}\right)$ by $\mathrm{NaClO}\left(3.8 \times 10^{-3} \mathrm{M}\right)$ were recorded for three different [1a] values: $1.99 \times 10^{-7} \mathrm{M}, 3.98 \times 10^{-7} \mathrm{M}$, and $1.66 \times 10^{-6} \mathrm{M}$ (Fig. 2). As shown in Table 2 and Fig. S2, the initial rates of Met consumption increased linearly with [1 $\mathbf{1}$ ] but the TON did not remain constant. At [1a] of $1.99 \times 10^{-7} \mathrm{M}$ and $3.98 \times 10^{-7} \mathrm{M}$, TONs of $\sim 100$ are observed. However, at [1a] of $1.66 \times 10^{-6}$ $\mathrm{M}$, the TON decreased by $\sim 60 \%$ - the corresponding $\% \mathrm{Cvn}$ values are $7.8,14.4$ and $21 \%$. In each case, approximately half of the theoretical amount of acetic acid, the only observable major product, is produced (kinetic traces of acetic acid generation are shown in Fig. S3). At the lower two [1a] values the $\mathrm{NaClO}$ catalysis is observed to function for about $90 \mathrm{~h}$, but at the highest [1a] the catalysis lasts only $30 \mathrm{~h}$. Typically, TAML catalysis is conducted with excess oxidant and stops when all of the catalyst is inactivated. Catalysis resumes upon introduction of a fresh TAML dose. ${ }^{14,}{ }^{32-33,36}$ In the $\mathbf{1 a} / \mathrm{NaClO}$ experiment with $[\mathbf{1 a}]=1.66 \times 10^{-6} \mathrm{M}$, Met consumption did not resume after introducing an additional dose of 1a or of $\mathrm{NaClO}\left(3.51 \times 10^{-4} \mathrm{M}\right)$ at $50 \mathrm{~h}($ Fig. S4), giving evidence for both irreversible catalyst inactivation and complete oxidant consumption. This behavior is unusual and is being examined further.

In both the $\mathrm{H}_{2} \mathrm{O}_{2}$ and $\mathrm{NaClO}$ systems, catalyst lifetime and TON diminished significantly on increasing [1a] from 1.99$3.98 \times 10^{-7} \mathrm{M}$ to $1.66 \times 10^{-6} \mathrm{M}$. This suggested that higher order catalyst degradation processes in [1a] became kinetically relevant. We have previously considered the role of inactivation pathways that are bimolecular in catalyst, labeled $k_{2 \mathrm{i}}$ processes (Scheme 1), in TAML catalysis, and estimated that contributions from such pathways are negligible at catalyst concentrations $<1 \times 10^{-6} \mathrm{M}^{32-33,36-37}$ These experimental results support the prior estimates. The detection of these higher order processes here suggests a $k_{2 \mathrm{i}}$ pathway in both systems. However, increasing [1a] impacted the $\mathrm{H}_{2} \mathrm{O}_{2}$ and $\mathrm{NaClO}$ processes differently. In the $\mathrm{NaClO}$ system, increasing [1a] from $3.98 \times 10^{-7} \mathrm{M}$ to $1.66 \times 10^{-6} \mathrm{M}$ gave a $6.6 \%$ increase in the percent of Met oxidized (Table 1). In the $\mathrm{H}_{2} \mathrm{O}_{2}$ system, this same [1a] increase reduced Met oxidation from $4.3 \%$ to effectively zero within experimental error (Figs. 2 and S5). We have interpreted this loss of catalysis in the following way.

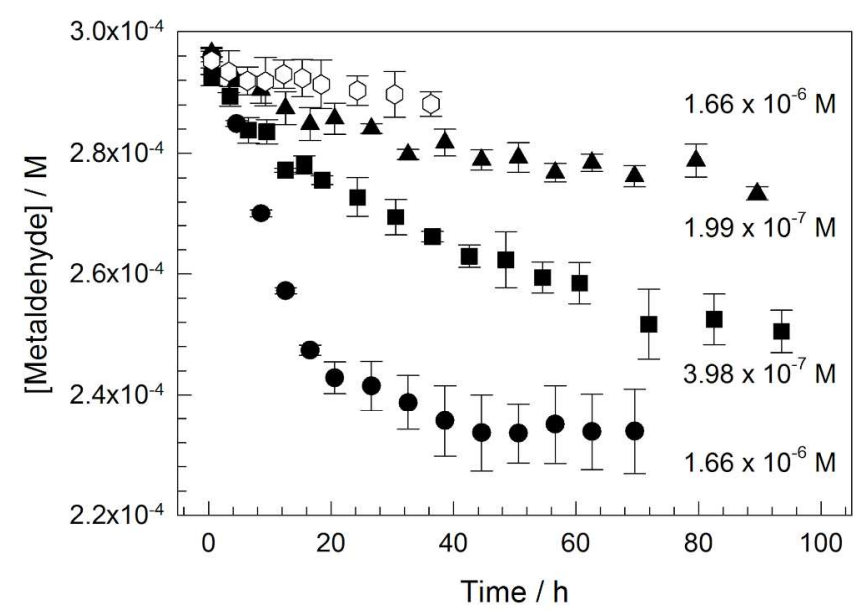

Figure 2. Kinetic traces of 1a catalyzed metaldehyde oxidation. [1a] values are shown on the figure next to the corresponding kinetic traces. Hollow hexagons: $\left[\mathrm{H}_{2} \mathrm{O}_{2}\right]=3.61 \times 10^{-3} \mathrm{M}(12.2$ equivalents); Black symbols: $[\mathrm{NaClO}]=3.8 \times 10^{-3} \mathrm{M}(12.8$ equivalents). Other conditions: $\mathrm{pH} 7 \mathrm{D}_{2} \mathrm{O}(0.01 \mathrm{M}$, phosphate), $[\mathrm{Met}]_{0}=2.95 \times 10^{-4} \mathrm{M}$.

If for the $\mathrm{H}_{2} \mathrm{O}_{2}$ case with $[\mathbf{1 a}]=1.66 \times 10^{-6} \mathrm{M}$, eq 3 is applied using the estimated $k_{\text {II }}$ of $120 \pm 30 \mathrm{M}^{-1} \mathrm{~s}^{-1}$ and setting an approximation for the oxidation percentage of $2 \%$ (Fig. S5; to avoid a zero denominator), the estimated total $k_{\mathrm{i}}$ value is ca. $1.0 \times 10^{-2} \mathrm{~s}^{-1}$. This is an order of magnitude greater than the $k_{\mathrm{i}}$ for $1 \mathrm{a} / \mathrm{H}_{2} \mathrm{O}_{2}$ measured at $[\mathbf{1 a}] \approx 10^{-8} \mathrm{M}$ where inactivation is exclusively unimolecular in catalyst. ${ }^{33}$ These results suggest the operation of inactivation processes that are bimolecular in catalyst at $[\mathbf{1 a}] \geq$ ca. $1 \times 10^{-6} \mathrm{M}$ which greatly outpace those that are unimolecular in catalyst. Equation 3 is very sensitive to the estimated oxidation percentage. If values $<2 \%$ are chosen instead, even higher $k_{\mathrm{i}}$ values result. Application of eq 3 to the analogous $\mathrm{NaClO}$ process with $[\mathbf{1 a}]=1.66 \times 10^{-6} \mathrm{M}$ gives a $k_{\mathrm{i}}$ of $8.5 \times 10^{-4} \mathrm{~s}^{-1}$. This is at least one order of magnitude 
Table 2. Summary of metaldehyde degradation at different $[1 \mathrm{la}]$ values; $[\mathrm{Met}]=2.95 \times 10^{-4} \mathrm{M},[\mathrm{NaClO}] \approx 3.8 \times 10^{-3} \mathrm{M}$.

\begin{tabular}{cccccc}
\hline$[\mathbf{1 a}] \times 10^{-7} \mathrm{M}$ & $v \times 10^{8} / \mathrm{M} \mathrm{min}^{-1 \mathrm{a}}$ & $\mathrm{TON}$ & $\% \mathrm{Cvn}$ & Acetic acid formed $/ \%{ }^{\mathrm{b}}$ & $\mathrm{t}_{\infty}{ }^{\mathrm{c}} / \mathrm{h}$ \\
\hline 1.99 & $1.2 \pm 0.2$ & $116 \pm 6$ & $7.8 \pm 0.4$ & $4.1 \pm 0.1$ & 90 \\
3.98 & $2.0 \pm 0.2$ & $106 \pm 6$ & $14.4 \pm 0.9$ & $9.0 \pm 0.7$ & 90 \\
16.6 & $5.4 \pm 0.1$ & $37 \pm 5$ & $21 \pm 3$ & $10 \pm 1$ & 30
\end{tabular}

${ }^{\mathrm{a}}$ The rate $v$ was calculated from the slope of the line of best fit to the first five [Met] measurements $(v=\mathrm{d}[\mathrm{Met}] / \mathrm{dt}){ }^{\mathrm{b}}{ }^{\mathrm{T}} \mathrm{he}$ percentage of acetic acid (AA) formation was calculated from the $\mathrm{CH}_{3}$ absolute integral relative to the initial metaldehyde signal $(\mathrm{AA} \%=(\mathrm{Ab}$ $\left.\left.{ }^{\mathrm{s}} \mathrm{Int}_{1.92}\right) /\left({ }^{\mathrm{Abs}} \mathrm{Int}_{1.34}\right)_{0} \times 100\right) ;{ }^{\mathrm{c}}$ Reaction time.

less than the corresponding $\mathrm{H}_{2} \mathrm{O}_{2}$ value and is comparable to the $k_{\mathrm{i}}$ value observed for the lower [1a] $\mathrm{H}_{2} \mathrm{O}_{2}$ systems. Thus, one can deduce that at high [1a], the use of $\mathrm{NaClO}$ results in productive catalysis by avoiding $k_{2 \mathrm{i}}$ processes observed in the $\mathrm{H}_{2} \mathrm{O}_{2}$ system. However, the eq 3 calculated $k_{\mathrm{i}}$ for the [1a] $=$ $1.66 \times 10^{-6} \mathrm{M} \mathrm{NaClO}$ system is ca. threefold greater than that of the lower [1a] $\mathrm{NaClO}$ experiments, indicating that $k_{2 \mathrm{i}}$ processes operate in the $\mathrm{NaClO}$ system. These results highlight the importance of developing kinetic approaches for determining the mechanism(s) and rate constant(s) of the $k_{2 i}$ process(es). Such studies are ongoing, and the understanding gained through them is expected to aide in the design of superior catalysts for high [TAML] processes.

More complete metaldehyde removal with continuous additions of catalyst and oxidant. As a result of $k_{2 \mathrm{i}}$ processes, deeper Met removals are more efficiently accomplished by using multiple catalyst doses to ensure that $[\mathbf{1 a}]<\mathrm{ca} .1 \times 10^{-6}$ M. The optimized catalyst dose was that giving a [1a] of $4 \times$ $10^{-7} \mathrm{M}$. The data shown in Fig. 3 represent two separate experiments demonstrating the efficacy of multiple catalyst doses each giving a [1a] of $4 \times 10^{-7} \mathrm{M}$. Experiment 1 employed a $[\text { Met }]_{0}$ of $3.32 \times 10^{-4} \mathrm{M}$ (Fig. 3 solid circles and Fig. S6). Since Met mineralization requires 20 equivalents of $\mathrm{NaClO}$, a slight excess $\left(7.61 \times 10^{-3} \mathrm{M}\right)$ was added. The first catalyst dose consumed Met for $72 \mathrm{~h}$ before the reaction ceased. Seven additional 1a doses were added leading to a slow oxidation of $75.3 \%$ over $576 \mathrm{~h}$. After the addition of the fifth catalyst dose, the position of the $\mathrm{CH}_{3} \mathrm{COO}^{-1} \mathrm{H}$ NMR signal at $1.956 \mathrm{ppm}$ indicated a solution $\mathrm{pH}$ of 5.2, 1.8 units less than the initial $\mathrm{pH}$ of 7 (Fig. S7). ${ }^{14,} 40$ Therefore at $360 \mathrm{~h}$, enough additional $\mathrm{NaClO}$ was added to raise the $[\mathrm{NaClO}]$ by $4.79 \times 10^{-3} \mathrm{M}$. This addition returned the $\mathrm{CH}_{3} \mathrm{COO}^{-}$signal to its initial value while providing additional oxidant. The initial metaldehyde concentration $\left([\mathrm{Met}]_{0}\right)$, change in metaldehyde concentration $(\Delta[\mathrm{Met}])$, TON, and $\%$ Cvn for each catalyst dose are summarized in Table S4. For all catalyst doses, $\Delta[\mathrm{Met}]$ and TON declined with $[\mathrm{Met}]_{0}$.

In Experiment 2, the oxidation of a fresh $1.12 \times 10^{-4} \mathrm{M}$ Met solution was studied (Fig. 3 hollow squares and Fig. S8) to examine if the accumulating acetate or inactivated catalyst products were contributing to the deterioration in $\Delta[\mathrm{Met}]$ and TON. ${ }^{41}$ For each catalyst dose of Experiment 2, the $[\mathrm{Met}]_{0}$, $\Delta$ [Met], TON, and \%Cvn are also summarized in Table S4. There is considerable agreement between the data sets. If the concentration of Met is followed along the black dotted curve of Experiment 1 through the white squares of Experiment 2, the result is representative of one continuous degradation process. Here, a ca. one order of magnitude reduction in [Met] $(330-30 \mu \mathrm{M})$ by less than $0.02 \mathrm{M} \mathrm{NaClO}$ can be achieved in $\sim 47$ days through treatment with 16 doses of 1 a each giving a solution [1a] of $4.0 \times 10^{-7} \mathrm{M}$. The combined process would consume less than 60 equivalents of $\mathrm{NaClO}$ and proceed with a TON of 66 . This is significantly less than the Experiment 1 dose 1 TON of $112 \pm 6$. Both $\Delta[\mathrm{Met}]$ and TON decline steadily with $[\mathrm{Met}]_{0}$ (Table S4) for all Experiment 1 and 2 catalyst doses. The average $k_{\mathrm{i}}$ value of $(3 \pm 1) \times 10^{-4} \mathrm{M}$ is identical to the single catalyst dose value calculated from the data in Table 1. The combined data set has the following broad implications for ultra-dilute TAML catalysis with $\mathrm{Fe}_{\text {Tot }}<1 \times 10^{-6} \mathrm{M}$ (where no $k_{2 \mathrm{i}}$ processes are observed).

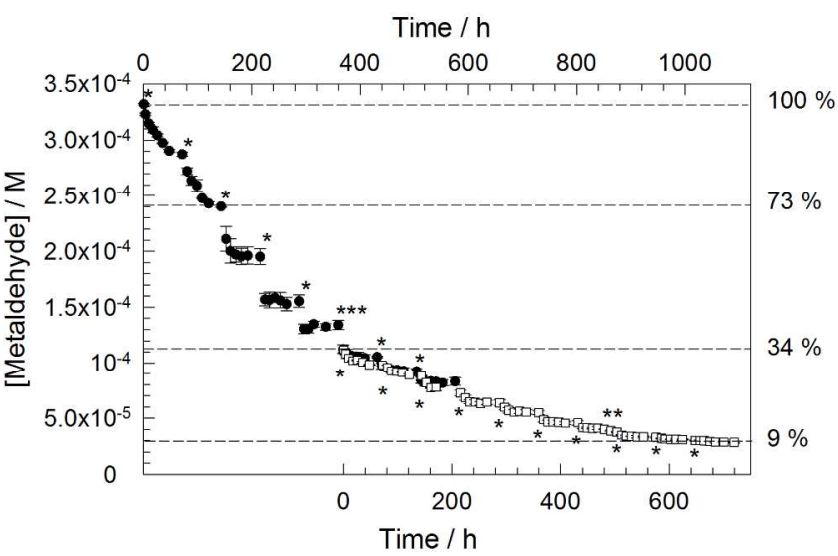

Figure 3. Kinetic traces of metaldehyde degradation by $\mathrm{NaClO}$ catalyzed by $1 \mathrm{a}$ in $\mathrm{pH} 7.0 \mathrm{D}_{2} \mathrm{O}(0.01 \mathrm{M}$, phosphate). Two experiments are shown. Experiment 1: solid circles $(\mathbf{O})$ and top time axis, $[\mathrm{Met}]_{0}=3.32 \times 10^{-4} \mathrm{M},[\mathbf{1 a}]=4.0 \times 10^{-7} \mathrm{M},[\mathrm{NaClO}]=7.61$ $\times 10^{-3} \mathrm{M}$. Experiment 2: hollow squares $(\square)$ and bottom time axis, $[\mathrm{Met}]_{0}=1.12 \times 10^{-4} \mathrm{M},[\mathbf{1 a}]=4.0 \times 10^{-7} \mathrm{M},[\mathrm{NaClO}]=4.71$

$\times 10^{-3} \mathrm{M}$. For both experiments: $*$ indicates the addition of one 4.0 $\times 10^{-7} \mathrm{M}$ catalyst dose, $* *$ indicates the addition of $\mathrm{NaClO}$ sufficient to raise the $[\mathrm{NaClO}]$ by $3.44 \times 10^{-3} \mathrm{M}, * * *$ indicates the addition of one catalyst dose giving a [1a] of $4.0 \times 10^{-7} \mathrm{M}$ and $\mathrm{NaClO}$ sufficient to raise the $[\mathrm{NaClO}]$ by $4.79 \times 10^{-3} \mathrm{M} \mathrm{NaClO}$.

First, dilution of the substrate poses a formidable challenge to ultradilute catalysis by diminishing the rate of substrate transformation without altering the rate of catalyst inactivation. By adapting eq 3 , a relation previously derived for the determination of $k_{\mathrm{i}}$ values ${ }^{32}$ and recently used to determine the $k_{\mathrm{i}}$ values for 15 TAML catalysts in the $\mathrm{pH} 7$ oxidation of Orange II (OrII) ${ }^{33}$ new forms which model the change in substrate concentration $(\Delta \mathrm{S}$, eq 4$), \%$ conversion $(\% \mathrm{Cvn}$, eq 5$)$ and the TON (eq 6) can be obtained and fit to the Met data where $\mathrm{S}_{0}=$ $[\mathrm{Met}]_{0}, \mathrm{~S}_{\infty}=[\mathrm{Met}]_{\infty}$, and $\Delta \mathrm{S}=\Delta \mathrm{Met}$. These new forms turn out to be very useful in developing the map and in better understanding the meaning of TON where the catalyst is degrading. In the oxidation of any substrate under any one set of conditions, both $k_{\mathrm{II}}$ and $k_{\mathrm{i}}$ are fixed. For a fixed catalyst dose (FeTot), the ratio of these dictates the change in substrate concentration $(\Delta S)$ and the TON, both of which decline with the initial substrate concentration $\left(\mathrm{S}_{0}\right)$ as shown in eqs 4 and 6 . The Met data confirm this (Fig. 4). The mathematical treatment 
that resulted in eq 3 considered all of the events shown in Scheme 1 to arrive at the most general expression. ${ }^{32}$ Contributions from the catalyst activation process $k_{\mathrm{I}}$ are absent from this form indicating that $\mathrm{S}_{\infty}$, and thus $\Delta \mathrm{S}$ and TON, are determined by the competition for Ac between the substrate oxidation $\left(-\mathrm{d}[\mathrm{S}] / \mathrm{dt}=k_{\mathrm{II}}[\mathrm{S}][\mathrm{Ac}]\right)$ and catalyst inactivation $(\mathrm{d}[\mathrm{Ic}] / \mathrm{dt}=$ $\left.k_{\mathrm{i}}[\mathrm{Ac}]\right)$ processes alone. The rate of the former depends on the [S] while that of the latter does not. As a result, $\Delta \mathrm{S}$ declines with $\mathrm{S}_{0}$. This dynamic is especially important when the substrate is ultra-dilute as is the usual case with MPs in municipal wastewater.

$$
\begin{aligned}
& \Delta \mathrm{S}=\mathrm{S}_{0}\left(1-e^{-\frac{k_{\mathrm{II}}}{k_{\mathrm{i}}} \mathrm{Fe}_{\mathrm{Tot}}}\right) \\
& \% C v n=\frac{\Delta \mathrm{S}}{\mathrm{S}_{0}} \times 100 \%=\left(1-e^{-\frac{k_{\mathrm{II}}}{k_{\mathrm{i}}} \mathrm{Fe}_{\mathrm{Tot}}}\right) \times 100 \% \\
& \mathrm{TON}=\frac{\left(1-e^{-\frac{k_{\mathrm{II}}}{k_{\mathrm{i}}} \mathrm{Fe}_{\mathrm{Tot}}}\right)}{\mathrm{Fe}_{\mathrm{Tot}}} \mathrm{S}_{0}
\end{aligned}
$$

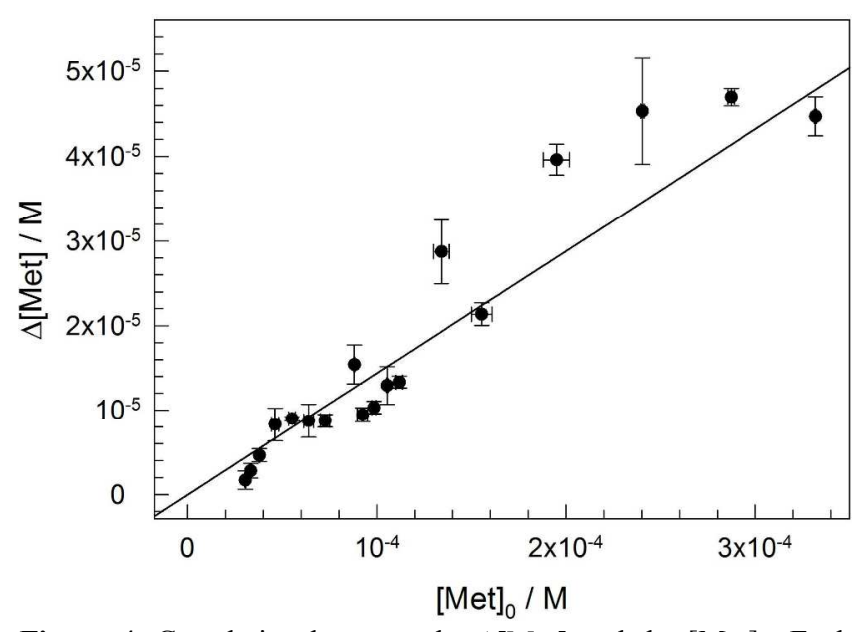

Figure 4. Correlation between the $\Delta[\mathrm{Met}]$ and the $[\mathrm{Met}]_{0}$. Each data point represents the $\Delta$ [Met] for each Experiment 1 or 2 catalyst dose. The line gives the eq 5 predicted $\Delta\left[\right.$ Met] values with $k_{\mathrm{i}}$ $=3.0 \times 10^{-4} \mathrm{~s}^{-1}, k_{\mathrm{II}}=120 \mathrm{M}^{-1} \mathrm{~s}^{-1}$, and $[\mathbf{1 a}]=4.0 \times 10^{-7} \mathrm{M}$. The other conditions are as indicated in the Fig. 3 caption and Table S4.

Second, from $\mathrm{pH} 5.2-7$, the oxidant independent 1a inactivation process operates via a mechanism that is sensitive to the Lewis acidity at Fe. The linearity found in Fig. 4 indicates that a constant $k_{\mathrm{II}} / k_{\mathrm{i}}$ ratio holds for all of the catalyst doses of both experiments. The data were collected at varying $\mathrm{pH},[\mathrm{NaClO}]$, [product], and [Ic] such that the linear relationship of Fig. 4 also establishes that these parameters do not alter $k_{\mathrm{II}} / k_{\mathrm{i}}$ implying that inhibition by product or inactive catalyst species and $\mathrm{NaClO}$ dependent inactivation processes are negligible. The data in Fig. 4 were collected at $\mathrm{pH}$ values over the range of 5.2-7. TAML $k_{\mathrm{II}}$ values have been observed to increase with $\mathrm{pH}$ by more than an order of magnitude from $\mathrm{pH} 6-7 .{ }^{42}$ Therefore, the $1 \mathrm{a} / \mathrm{NaClO} k_{\mathrm{II}}$ and $k_{\mathrm{i}}$ must track each other closely over this range as was found in catalysis by 15 TAML activators with $\mathrm{H}_{2} \mathrm{O}_{2}$ at $\mathrm{pH} 7 .{ }^{33}$ We have interpreted these fixed $k_{\mathrm{II}} / k_{\mathrm{i}}$ ratios as evidence that the Lewis acidity at Fe exerts a common influence over both $k_{\text {II }}$ and $k_{\text {i }}$ processes at $\mathrm{pH} 7$, but for the $\mathrm{H}_{2} \mathrm{O}_{2}$ systems we were unable to determine whether the ratio mandated changes in $k_{\mathrm{i}}$ derive from the $\mathrm{H}_{2} \mathrm{O}_{2}$ dependent or independent processes, or both. Since contributions from $\mathrm{NaClO}$ dependent inactivation are negligible, the mandatory changes in $k_{\mathrm{i}}$ must originate from $\mathrm{NaClO}$ independent processes which operate from $\mathrm{pH} 5.2$ to 7 . Because the $\mathrm{NaClO}$ and $\mathrm{H}_{2} \mathrm{O}_{2}$ Ac are similar and the observed dependence on Lewis acidity is independent of oxidant, it is therefore likely that similar processes are operating in the $\mathrm{H}_{2} \mathrm{O}_{2}$ systems.

Third, while most MPs can be effectively treated by existing TAML systems operating under ultra-dilute aqueous conditions, those having $k_{\mathrm{II}} / k_{\mathrm{i}}$ ratios $\leq 1 \times 10^{6} \mathrm{M}^{-1}$ cannot. As noted, when $[\mathbf{1 a}]>1 \times 10^{-6} \mathrm{M}$, contributions to $k_{\mathrm{i}}$ from decomposition processes that are second order in [1a] $\left(k_{2 \mathrm{i}}\right.$ processes) become significant. Therefore, we consider an $\mathrm{Fe}_{\mathrm{Tot}}$ of $1 \times 10^{-6}$ $\mathrm{M}$ to be an upper bound for effective ultra-dilute catalysis. In principle, below this, eqs 3-6 model the $\mathrm{S}_{\mathrm{o}} / \mathrm{S}_{\infty}$ ratio, \%Cvn, and TON in TAML catalysis for the oxidation of any substrate by any oxidant with any catalyst under any conditions provided inactivation also occurs from Ac and neither the substrate nor the products perturb the catalytic cycle (e.g. substrate binding to the catalyst). However, it should be noted that the critical dimension of time is not captured by eqs 3-6 and thus cannot be included in the following discussion - we are further considering how to address the time dimension.

Using the known $k_{\mathrm{II}}$ and $k_{\mathrm{i}}$ values, eq 5 predicts within $\pm 3 \%$ the observed experimental $5 \% \mathrm{Cvn}$ of Met found for $1 \mathrm{a} / \mathrm{H}_{2} \mathrm{O}_{2}$ treatment $\left([\mathbf{1 a}]=4 \times 10^{-7} \mathrm{M}\right)$ in $\mathrm{pH} 7$ buffered $\mathrm{D}_{2} \mathrm{O}(0.01 \mathrm{M}$ phosphate), the $(14.4 \pm 0.9) \% \mathrm{Cvn}$ of Met for $1 \mathrm{a} / \mathrm{NaClO}$ treatment $\left([\mathbf{1 a}]=4 \times 10^{-7} \mathrm{M}\right)$ in $\mathrm{pH} 7$ buffered $\mathrm{D}_{2} \mathrm{O}(0.01 \mathrm{M}$ phosphate), the $18 \% \mathrm{Cvn}$ of the persistent SSRI Sertraline (Ser) for $1 \mathbf{a} / \mathrm{H}_{2} \mathrm{O}_{2}$ treatment $\left([\mathbf{1 a}]=3 \times 10^{-7} \mathrm{M}\right)$ in $\mathrm{pH} 7$ buffered $\mathrm{H}_{2} \mathrm{O}(0.01 \mathrm{M}$ phosphate), the $27 \% \mathrm{Cvn}$ of the azo dye Orange II (OrII) for $\mathbf{1 b} / \mathrm{H}_{2} \mathrm{O}_{2}$ treatment $\left([\mathbf{1 b}]=2 \times 10^{-8} \mathrm{M}\right)$ in pH 7 buffered $\mathrm{H}_{2} \mathrm{O}(0.01 \mathrm{M}$ phosphate), the $>98 \% \mathrm{Cvn}$ of $17 \alpha$-ethynylestradiol (EE2) for $\mathbf{1 b} / \mathrm{H}_{2} \mathrm{O}_{2}$ treatment $([\mathbf{1 b}]=8 \times$ $\left.10^{-8} \mathrm{M}\right)$ in $\mathrm{pH} 7$ buffered $\mathrm{H}_{2} \mathrm{O}(0.01 \mathrm{M}$ phosphate $),{ }^{43}$ and the $17 \%$ Cvn of the dye Safranin O (SO) in pH 11 buffered $\mathrm{H}_{2} \mathrm{O}$ $\left([\mathbf{1 a}]=7.5 \times 10^{-8} \mathrm{M}\right) .{ }^{36}$ Figure 5 is a helpful graphical representation of eq 5 onto which these processes can be plotted. The $k_{\mathrm{II}}$ value for $1 \mathrm{a}$ oxidation Met in both the $\mathrm{H}_{2} \mathrm{O}_{2}$ and $\mathrm{NaClO}$ systems, $120 \mathrm{M}^{-1} \mathrm{~s}^{-1}$, is the lowest of any MP we have ever tested. The $k_{\text {II }}$ value for $\mathbf{1} \mathbf{b} / \mathrm{H}_{2} \mathrm{O}_{2}$ oxidation of EE2 at $\mathrm{pH}$ $7,8.6 \times 10^{5} \mathrm{M}^{-1} \mathrm{~s}^{-1}$, is the highest. ${ }^{12}$ The value for $\mathbf{1 a} / \mathrm{H}_{2} \mathrm{O}_{2}$ oxidation of Ser, $740 \mathrm{M}^{-1} \mathrm{~s}^{-1}$, is closer to the Met than the EE2 value as expected. The value for $\mathbf{1 b} / \mathrm{H}_{2} \mathrm{O}_{2}$ oxidation OrII, $4,950 \mathrm{M}^{-1} \mathrm{~s}^{-1}$, is closer to the EE2 than the Met value as expected. Thus eqs. 3-6 hold over a ca. $10^{4} \mathrm{M}^{-1}$ range of $k_{\mathrm{II}} / k_{\mathrm{i}}$ for two catalysts and oxidants and at $\mathrm{pH} 7$ and 11 , adding confidence to both the validity and generality of the analytical model for both academic and real-world applications.

Typically, water treatment plants are driven by a need to achieve regulated levels rather than complete removal of pollutants. Equation 5 could be used to predict the optimal catalyst loading, $\mathrm{Fe}_{\mathrm{Tot}}$ (below $1 \times 10^{-6} \mathrm{M}$ ), needed to effect a given $\%$ Cvn of any MP under any one set of conditions from data obtained by measuring one incomplete kinetic trace at a known $\mathrm{Fe}_{\mathrm{Tot}}$ which gives $k_{\mathrm{II}} / k_{\mathrm{i}}$. This will always hold provided the process is rapid enough to be deployable. If $k_{\mathrm{i}}$ is known under these conditions, $k_{\mathrm{II}}$ is also known - an extensive series of $\mathrm{pH} 7 k_{\mathrm{i}}$ values for TAMLs have been determined. ${ }^{33}$ We are 


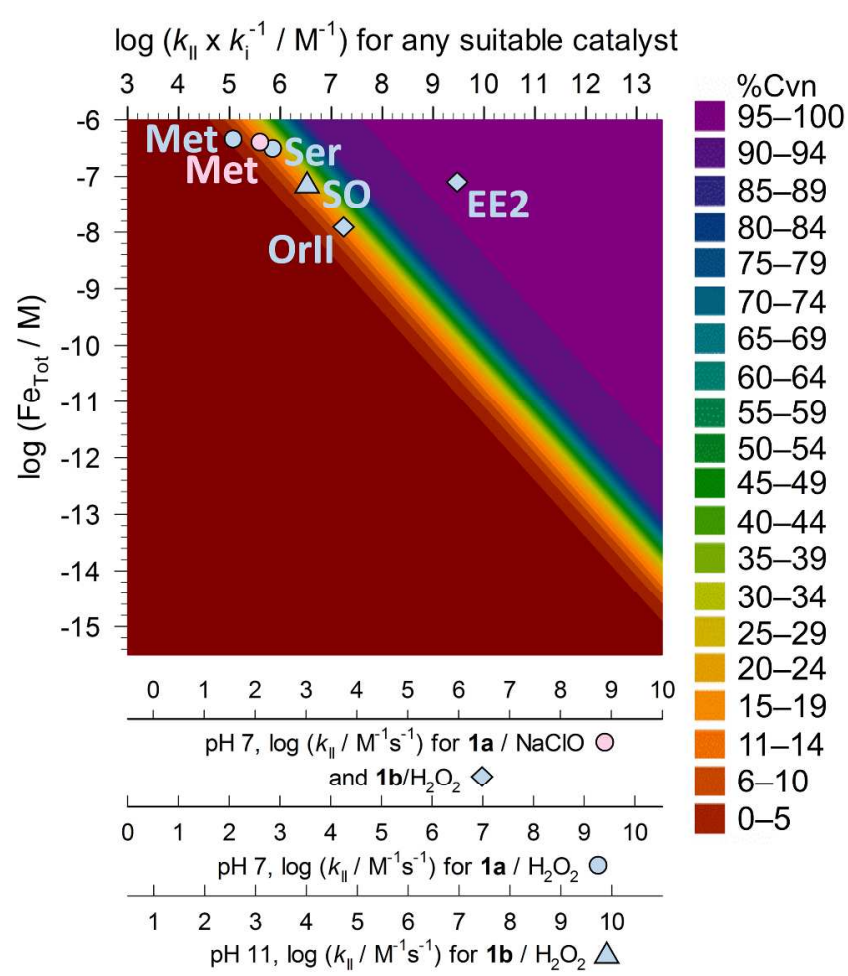

Figure 5. The eq 5 predicted $\% \mathrm{Cvn}$ as a function of $\log \left(\mathrm{Fe}_{\text {Tot }}^{\mathrm{III}}\right)$ and either $\log \left(k_{\mathrm{II}} / k_{\mathrm{i}}\right)$ for treatment with any suitable catalyst (top axis), $\log \left(k_{\mathrm{II}}\right)$ for $\mathrm{pH} 7$ treatment with $\mathbf{1 a} / \mathrm{NaClO}$, $\log \left(k_{\mathrm{II}}\right)$ for $\mathrm{pH} 7$ treatment with $\mathbf{1} \mathbf{b} / \mathrm{H}_{2} \mathrm{O}_{2}, \log \left(k_{\mathrm{II}}\right)$ for $\mathrm{pH} 7$ treatment with $1 \mathrm{a} / \mathrm{H}_{2} \mathrm{O}_{2}$, or $\log \left(k_{\mathrm{II}}\right)$ for $\mathrm{pH} 11$ treatment with $\mathbf{1 b} / \mathrm{H}_{2} \mathrm{O}_{2}$ (bottom axes which shift with different oxidants and $\mathrm{pHs}$ ). The points shown indicate experimental data for conversion of various substrates having the identities indicated in the text. The $k_{\mathrm{II}}, k_{\mathrm{i}}$, and $\%$ Cvn values for each data point were obtained individually.

treating a larger set of MPs and examining the behavior of additional catalysts over a wider $\mathrm{pH}$ range to obtain $k_{\mathrm{II}}, k_{\mathrm{i}}$, and $\% \mathrm{Cvn}$ under different conditions to further cement the usefulness of this predictive tool.

The upper bound of the $\log \left(k_{\mathrm{II}} / k_{\mathrm{i}}\right)$ range shown in Fig. 5 (top horizontal axis) is set at the hypothetical diffusion controlled limit for $1 \mathrm{a} / \mathrm{NaClO}$ treatment at $\mathrm{pH} 7\left(k_{\mathrm{II}}\right.$ of ca. $10^{10} \mathrm{M}^{-1} \mathrm{~s}^{-1}$, topmost axis below figure).$^{44}$ In applying TAML processes to remove micropollutants, useful processes deliver $\% \mathrm{Cvn} \geq 50$. The equation predicts that sub-picomolar [1a] can effect 50 $\%$ Cvn for very rapidly oxidizing substrates. However, practical concerns such as reaction time will likely limit utility here-we are working to discover a similar tool for reaction time. The lower $k_{\mathrm{II}} / k_{\mathrm{i}}$ limit of the green band $(50 \% \mathrm{Cvn})$ is found at ca. $10^{6} \mathrm{M}^{-1}$. The $k_{\mathrm{II}} / k_{\mathrm{i}}$ ratios for TAML catalyzed oxidation of many MPs lie above this. However, this sets the lower $k_{\text {II }}$ bound for the most useful $1 \mathbf{a} / \mathrm{H}_{2} \mathrm{O}_{2}$ treatment with an $\mathrm{Fe}_{\mathrm{Tot}}$ of $1 \times 10^{-6} \mathrm{M}$ at ca. $1,100 \mathrm{M}^{-1} \mathrm{~s}^{-1}$ near $\mathrm{pH}$ 7. Substrates more slowly oxidized than this are not well treated with a single catalyst dose of $1 \mathbf{a} / \mathrm{H}_{2} \mathrm{O}_{2}$. The lower $k_{\mathrm{i}}$ of $1 \mathrm{a} / \mathrm{NaClO}$ treatment shifts this bound to ca. $300 \mathrm{M}^{-1} \mathrm{~s}^{-1}$. However, Met remains just out of reach with a $k_{\text {II }}$ of $120 \pm 30 \mathrm{M}^{-1} \mathrm{~s}^{-1}$. As the $1 \mathrm{a} / \mathrm{NaClO}$ data demonstrate, the key to extending ultra-dilute catalysis to more slowly transformed substrates is the development of systems that maximize the $k_{\mathrm{II}} / k_{\mathrm{i}}$ ratio by disproportionately increasing $k_{\mathrm{II}}$, decreasing $k_{\mathrm{i}}$, or both. An effective Met solution would require roughly a doubling of the $\mathbf{1 a} k_{\text {II }}$ value or halving of the $1 \mathrm{a} / \mathrm{NaClO} k_{\mathrm{i}}$ value while keeping the other constant. We are working towards achieving and exceeding this entirely realistic goal via iterative catalyst design.

Fourth, when $\mathrm{Fe}_{\text {Tot }} \leq \mathrm{ca} .1 \times 10^{-6} \mathrm{M}$, successive small catalyst doses are not more effective than larger catalyst doses. As indicated by eq 6 and Fig. 6, the dependence of TON on the $k_{\mathrm{II}} / k_{\mathrm{i}}$ ratio and $\mathrm{Fe}_{\mathrm{Tot}}$ is complex. We have interpreted the relationship in the following way. For any one catalyst operating under any one set of conditions, $k_{\mathrm{i}}$ is fixed. The value of the $k_{\mathrm{II}} / k_{\mathrm{i}}$ ratio then varies with $k_{\mathrm{II}}$. Thus, the value of $k_{\mathrm{II}}$ determines the dependence between TON and $\mathrm{Fe}_{\mathrm{Tot}}$ and places the oxidation process on a spectrum between two limits. At the low $k_{\text {II }}$ limit, when $k_{\mathrm{II}} \mathrm{Fe}_{\text {Tot }} / k_{\mathrm{i}}<1$, eq 6 can be approximated by the first term of a Maclaurin series, TON $\sim k_{\text {II }} \mathrm{S}_{0} / k_{\mathrm{i}}$ (contributions from the higher order terms of the series are negligible). Consequently, in the $1 \mathrm{a} / \mathrm{NaClO}$ conversion of slowly transformed Met, for which $k_{\mathrm{II}} / k_{\mathrm{i}}=4 \times 10^{5} \mathrm{M}^{-1}$, the TON is largely independent of $\mathrm{Fe}_{\mathrm{Tot}}$ as shown in Table 2 and along the surface of Fig. 6 at the low $k_{\mathrm{II}} / k_{\mathrm{i}}$ limit. In these oxidations, every catalyst molecule of any catalyst dose does about the same amount of work, and the \%Cvn scales linearly with $\mathrm{Fe}_{\mathrm{Tot}}$.

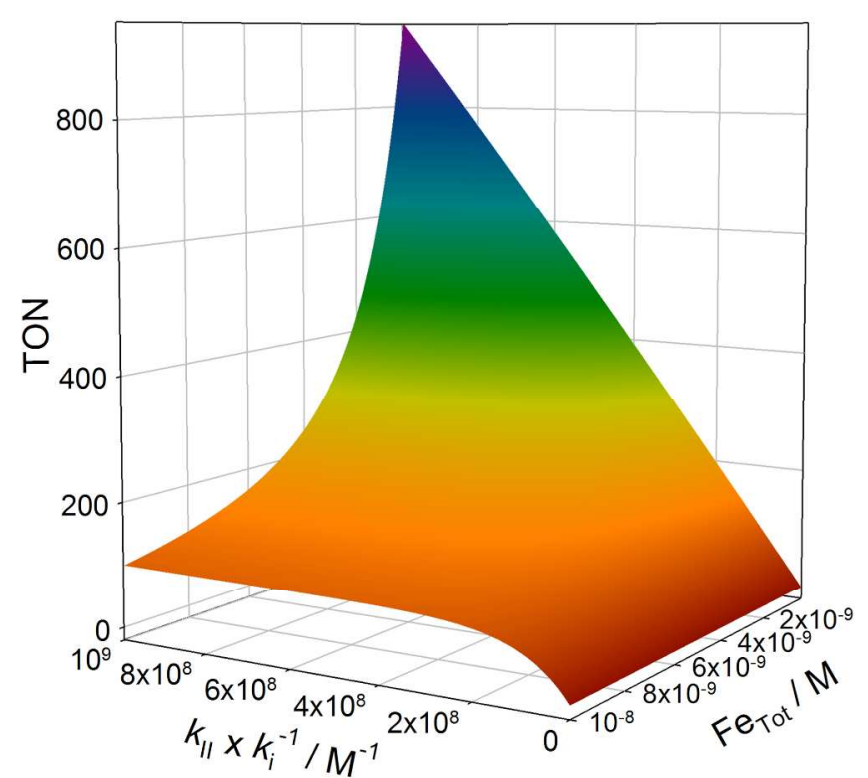

Figure 6. The eq 6 calculated dependence of the TON on $k_{\mathrm{II}} / k_{\mathrm{i}}$ and $\mathrm{Fe}_{\mathrm{Tot}}$ for a fixed $\mathrm{S}_{0}$ of $1 \times 10^{-6} \mathrm{M}$. From $\left[\mathrm{Fe}_{\mathrm{Tot}}\right] 10^{-8}-10^{-6} \mathrm{M}$ (not shown), the surface shape changes little from that shown at $\left[\mathrm{Fe}_{\mathrm{Tot}}\right]=10^{-8} \mathrm{M}$.

At the high $k_{\mathrm{II}}$ limit where $e^{-\frac{k_{\mathrm{II}}}{k_{\mathrm{i}}} \mathrm{Fe}_{\mathrm{Tot}}} \leq 0.1$, the numerator of eq 6 approaches 1 and TON $\sim \mathrm{S}_{0} / \mathrm{Fe}_{\text {Tot }}$. For example, for the $\mathbf{1 b} / \mathrm{H}_{2} \mathrm{O}_{2}$ treatment of EE2 introduced above, $k_{\mathrm{II}} / k_{\mathrm{i}}=2.9 \times 10^{9}$ $\mathrm{M}^{-1}$ and $e^{-\frac{k_{\mathrm{II}}}{k_{\mathrm{i}}} \mathrm{Fe}_{\mathrm{Tot}}}=2.5 \times 10^{-100}$. For treatment of such rapidly oxidized substrates, as $\mathrm{Fe}_{\text {Tot }}$ increases, so does $\Delta[\mathrm{S}]$ and with it the dilution of the substrate during functioning catalysis. This decreases the rate of substrate oxidation relative to that of catalyst inactivation causing average TONs to drop. This could lead one to suspect that treatment with multiple small catalyst doses would lead to improved performance. However, the use of multiple small catalyst doses is not more efficient at achieving a set \%Cvn than adding the equivalent $\mathrm{Fe}_{\text {tot }}$ in a single dose provided the sum of all doses is less than ca. $1 \times 10^{-6} \mathrm{M}$ because dilution lowers the average TON re- 
gardless of how the catalyst is administered (See the SI for a mathematical explanation of this). When eq 3 holds, a single TAML catalyst dose is optimal for most rapidly achieving a desired \%Cvn.

\section{Conclusion}

This study explores the behavior of TAML catalysis at the performance boundary prescribed by the exceptionally recalcitrant pollutant, Met. The findings communicated herein have broad significance for TAML catalysis. The rates of 1a catalyzed Met transformation by $\mathrm{NaClO}$ and $\mathrm{H}_{2} \mathrm{O}_{2}$ are identical giving a strong indication that the same reactive intermediate attacks Met in both systems. However, TAML/NaClO delivers a three-fold $k_{\mathrm{II}} / k_{\mathrm{i}}$ enhancement by lowering the rate of catalyst inactivation, which we attribute to elimination of contributions from $\mathrm{H}_{2} \mathrm{O}_{2}$ dependent inactivation processes. At $[\mathbf{1 a}]>1 \times 10$ ${ }^{6} \mathrm{M}$, inactivation pathways that are bimolecular in catalyst $\left(k_{2 \mathrm{i}}\right)$ and outpace those unimolecular in catalyst $\left(k_{\mathrm{i}}\right)$ render $\mathbf{1} \mathbf{a} / \mathrm{H}_{2} \mathrm{O}_{2}$ transformation of Met completely ineffective - this establishes an upper bound for [TAML] in $\mathrm{H}_{2} \mathrm{O}_{2}$ systems of $1 \mu \mathrm{M}$. The use of $\mathrm{NaClO}$ allows processes with [1a] $>1 \mu \mathrm{M}$ by restoring functioning catalysis indicating that both $k_{\mathrm{i}}$ and $k_{2 \mathrm{i}}$ are lower in the $\mathrm{NaClO}$ system. In both the $\mathrm{H}_{2} \mathrm{O}_{2}$ and $\mathrm{NaClO}$ systems, $k_{2 \mathrm{i}}$ processes outpace $k_{\mathrm{i}}$ processes. Further investigations of the mechanisms of the $k_{2 \mathrm{i}}$ processes and their dependences on the identity of the oxidant are underway. Application of eq 3 and forms derived from it to the Met data indicates that while $\Delta \mathrm{S}$ decreases with $\mathrm{S}_{0}, \%$ Cvn remains constant. The expression for TON provides a more detailed understanding of the underlying chemical processes as well as the effect of substrate dilution on this venerable metric for evaluating catalyst performance. This work demonstrates the advances in understanding which can be achieved through detailed analysis of the mechanisms of both catalyst operation and inactivation - the latter is a critical and underexplored territory.

\section{ASSOCIATED CONTENT}

Supporting Information. Details of metaldehyde degradation (Figs. S1-8); metaldehyde degradation summary (Tables S1-4). This material is available free of charge via the Internet at http://pubs.acs.org.

\section{AUTHOR INFORMATION}

Corresponding author: Phone: +1412268 6335; fax: +1 412 268 1061; E-mail: tc1u@andrew.cmu.edu (T.J.C.)

\section{Author Contributions}

All authors have given approval to the final version of the manuscript.

\section{Funding Sources}

T.J.C thanks the Heinz Endowments for funding. NMR instrumentation at CMU was partially supported by NSF (CHE0130903 and CHE-1039870).

\section{ACKNOWLEDGMENT}

T.J.C. thanks the Heinz Endowments for support. M.R.M thanks the Steinbrenner Institute and the R. K. Mellon Foundation for Doctoral Fellowships.

\section{ABBREVIATIONS}

MPs, micropollutants; Met, metaldehyde; AC, activated carbon; ppb, parts per billion; ppt, parts per trillion; Rc, resting catalysts; Ac, active catalysts; S, substrate; DBPs, disinfection byproducts; EE2, 17 $\alpha$-ethynylestradiol; $\quad$ TMSP, sodium-3trimethylsilylpropionate; NADH, $\beta$-nicotinamide adenine dinucleotide reduced.

\section{REFERENCES}

(1) Shane A. Snyder; Eric C. Wert; Hongxia Lei; Paul Westerhoff; Yoon, Y. Removal of EDCs and Pharmaceuticals in Drinking and Reuse Treatment Processes, 1st ed.; AwwaRF: Denver, 2007.

(2) Schwarzenbach, R. P.; Escher, B. I.; Fenner, K.; Hofstetter, T. B.; Johnson, C. A.; von Gunten, U.; Wehrli, B. Science 2006, 313, $1072-$ 1077 .

(3) McArdell, C. S. Norman Bulletin 2015, 36-37.

(4) Kundu, S.; Chanda, A.; Thompson, J. V. K.; Diabes, G.; Khetan, S. K.; Ryabov, A. D.; Collins, T. J. Catal. Sci. Technol. 2015, 5, 1775-1782.

(5) Kundu, S.; Chanda, A.; Khetan, S. K.; Ryabov, A. D.; Collins, T. J. Environ. Sci. Technol. 2013, 47, 5319-5326.

(6) Kundu, S.; Chanda, A.; Espinosa-Marvan, L.; Khetan, S. K.; Collins, T. J. Catal. Sci. Technol. 2012, 2, 1165-1172.

(7) Shen, L. Q.; Beach, E. S.; Xiang, Y.; Tshudy, D. J.; Khanina, N.; Horwitz, C. P.; Bier, M. E.; Collins, T. J. Environ. Sci. Technol. 2011, 45, 7882-7887.

(8) Beach, E. S.; Malecky, R. T.; Gil, R. R.; Horwitz, C. P.; Collins, T. J. Catal. Sci. Technol. 2011, 1, 437-443.

(9) Beach, E. S.; Duran, J. L.; Horwitz, C. P.; Collins, T. J. Ind. Eng. Chem. Res. 2009, 48, 7072-7076.

(10) Chanda, A.; Khetan, S. K.; Banerjee, D.; Ghosh, A.; Collins, T. J. J. Am. Chem. Soc. 2006, 128, 12058-12059.

(11) Banerjee, D.; Markley, A. L.; Yano, T.; Ghosh, A.; Berget, P. B.; Minkley, E. G.; Khetan, S. K.; Collins, T. J. Angew. Chem. Int. Edit. 2006, 45, 3974-3977.

(12) Mills, M. R.; Arias-Salazar, K.; Baynes, A.; Shen, L. Q.; Churchley, J.; Beresford, N.; Gayathri, C.; Gil, R. R.; Kanda, R.; Jobling, S.; Collins, T. J. Sci. Rep. 2015, 5, article number: 10511.

(13) Churchley, J.; Collins, T. J.; Jobling, S. Catalytic Oxidation of Pharmaceutical Compounds in Wastewater Effluents; London, UK, 2011.

(14) Tang, L. L.; DeNardo, M. A.; Gayathri, C.; Gil, R. R.; Kanda,

R.; Collins, T. J. Environ. Sci. Technol. 2016, 50, 5261-5268.

(15) Autin, O.; Hart, J.; Jarvis, P.; MacAdam, J.; Parsons, S. A.; Jefferson, B. Appl. Catal. B-Environ. 2013, 138, 268-275.

(16) James, C. P.; Germain, E.; Judd, S. Sep. Purif. Technol. 2014 $127,77-83$

(17) Scheideler, J.; Bosmith, A. Aqua Gas 2014, 94, 52-57.

(18) Collins, T. J.; Gordon-Wylie, S. W.; Horwitz, C. P. U.S Patent 6054580, 2000.

(19) Deborde, M.; von Gunten, U. Water Res. 2008, 42, 13-51.

(20) Collins, T. J.; Gordon-Wylie, S. W. U.S. Patent 5,847,120, 1998 .

(21) Mills, M. R.; Burton, A. E.; Mori, D. I.; Ryabov, A. D.; Collins, T. J. J. Coord. Chem. 2015, 68, 3046-3057.

(22) Ghosh, M.; Singh, K. K.; Panda, C.; Weitz, A.; Hendrich, M. P.; Collins, T. J.; Dhar, B. B.; Sen Gupta, S. J. Am. Chem. Soc. 2014, 136 , 9524-9527.

(23) Kundu, S.; Annavajhala, M.; Kurnikov, I. V.; Ryabov, A. D.; Collins, T. J. Chem. Eur. J. 2012, 18, 10244-10249.

(24) Fukuta, N. Nature 1963, 199, 475-476.

(25) Craven, E. C.; Jowitt, H.; Ward, W. R. J. Appl. Chem. 1962, $12,526-535$.

(26) Pauling, L.; Carpenter, D. C. J. Am. Chem. Soc. 1936, 58, 1274-1278.

(27) George, P. Biochem. J. 1953, 55, 220-230.

(28) Kelm, M.; Pashalidis, I.; Kim, J. I. Appl. Radiat. Isotopes 1999, $51,637-642$

(29) Edward M. Arnett; W. Emmett Barkley; Peter Beak; Edwin D. Becker; Henry E. Bryndza; Imogene L. Chang; Carol Creutz; Rick L. Danheiser; Eric M. Gordon; Robert J. Lackmeyer; Lee Magid; Thomas F. McBride; Ann M. Norberg; Edward W. Petrillo; Stanley H. Pine; Fay M. Thompson; Tamae Maeda Wong; Kasandra Gowen; Sarah W. Plimpton; Butera., J. F. Prudent Practices in the Laboratory: Handling and Disposal of Chemicals, National Academy Press: Washington, D.C., 1995.

(30) Sedlak, D. L.; von Gunten, U. Science 2011, 331, 42-43. 
(31) Yang, X.; Shang, C. Environ. Sci. Technol. 2004, 38, 49955001.

(32) Emelianenko, M.; Torrejon, D.; DeNardo, M.; Socolofsky, A.; Ryabov, A.; Collins, T. J. Math. Chem. 2014, 52, 1460-1476.

(33) DeNardo, M. A.; Mills, M. R.; Ryabov, A. D.; Collins, T. J. J. Am. Chem. Soc. 2016, 138, 2933-2936.

(34) Abe, K.; Hagiwara, J.; Machida, W. Taiki Osen Gakkaishi 1980, 15, 21-4.

(35) Bartos, M. J.; Gordon-Wylie, S. W.; Fox, B. G.; Wright, L. J.; Weintraub, S. T.; Kauffmann, K. E.; Munck, E.; Kostka, K. L.; Uffelman, E. S.; Rickard, C. E. F.; Noon, K. R.; Collins, T. J. Coordin. Chem. Rev. 1998, 174, 361-390.

(36) Chanda, A.; Ryabov, A. D.; Mondal, S.; Alexandrova, L.; Ghosh, A.; Hangun-Balkir, Y.; Horwitz, C. P.; Collins, T. J. Chem. Eur. J. 2006, 12, 9336-9345.

(37) Horwitz, C. P.; Fooksman, D. R.; Vuocolo, L. D.; GordonWylie, S. W.; Cox, N. J.; Collins, T. J. J. Am. Chem. Soc. 1998, 120, 4867-4868.

(38) Sen Gupta, S.; Stadler, M.; Noser, C. A.; Ghosh, A.; Steinhoff, B.; Lenoir, D.; Horwitz, C. P.; Schramm, K. W.; Collins, T. J. Science 2002, 296, 326-328
(39) Miller, J. A.; Alexander, L.; Mori, D. I.; Ryabov, A. D.; Collins, T. J. New J. Chem. 2013, 37, 3488-3495.

(40) Tynkkynen, T.; Tiainen, M.; Soininen, P.; Laatikainen, R. Anal. Chim. Acta. 2009, 648, 105-12.

(41) Crabtree, R. H. Chem. Rev. 2015, 115, 127-150.

(42) Warner, G. R.; Mills, M. R.; Enslin, C.; Pattanayak, S.; Panda, C.; Panda, T. K.; Sen Gupta, S.; Ryabov, A. D.; Collins, T. J. Chem. Eur. J. 2015, 21, 6226-6233.

(43) Mills, M. R. Synthesis, Characterization, and Unique Properties of a Novel, Completely Aliphatic TAML Activator and Applications of TAML Catalysis for Oxygen Evolution and Pollution Remediation. Carnegie Mellon University, Pittsburgh, PA, 2016.

(44) Koenig, S. H.; Brown, R. D. Proc. Nat. Acad. Sci. USA 1972 $69,2422-2425$. 


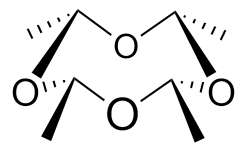

Metaldehyde (M I diastereomer)
$\mathrm{OH}_{2}$

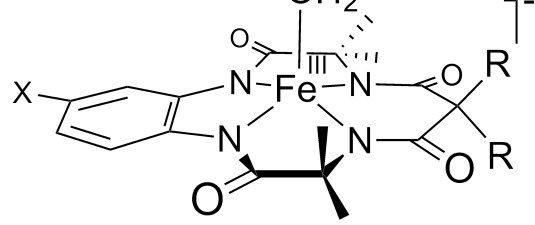

1a: $X=\mathrm{NO}_{2}, \mathrm{R}=\mathrm{F}$

1b: $X=H, R=M e$ 


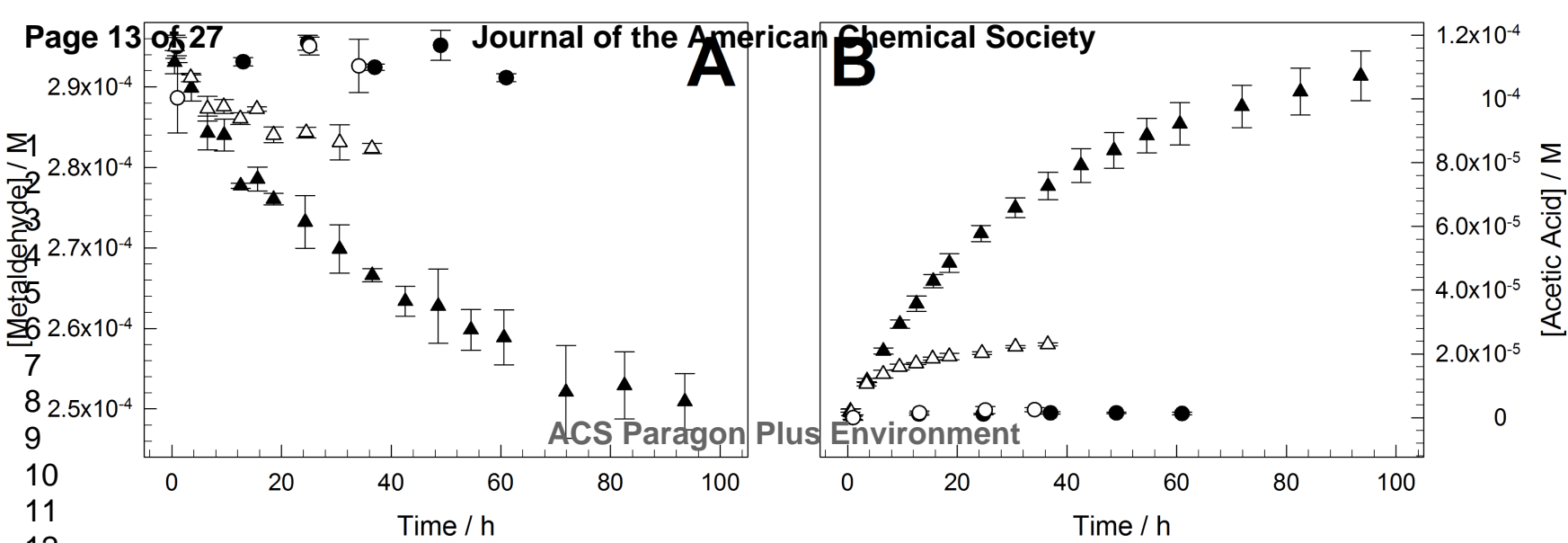


Substrate (S)

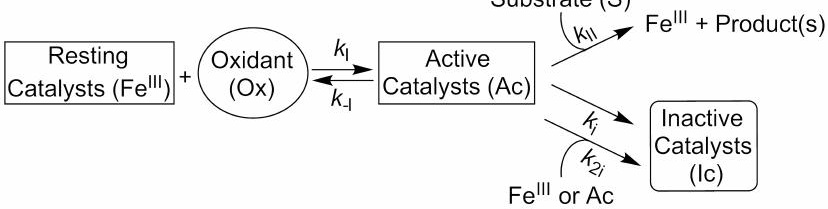


$3.0 \times 10^{-4}$

Pageur a e forthe American Chemical Society

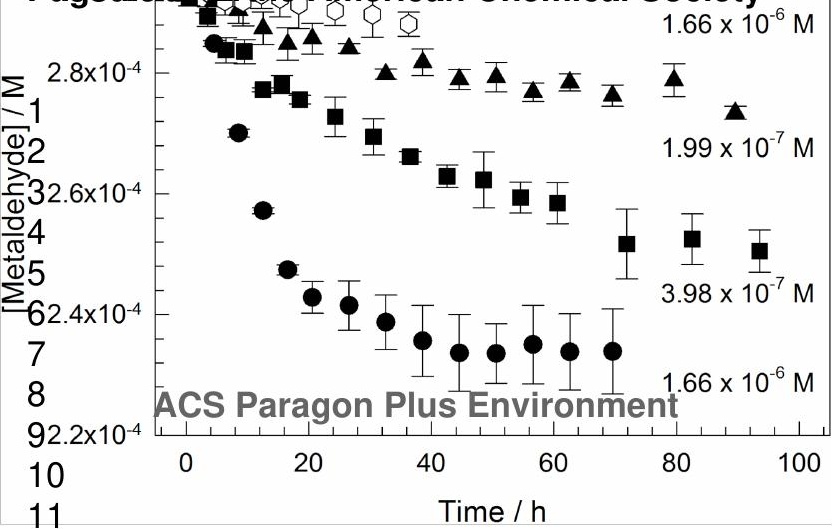


Time / h

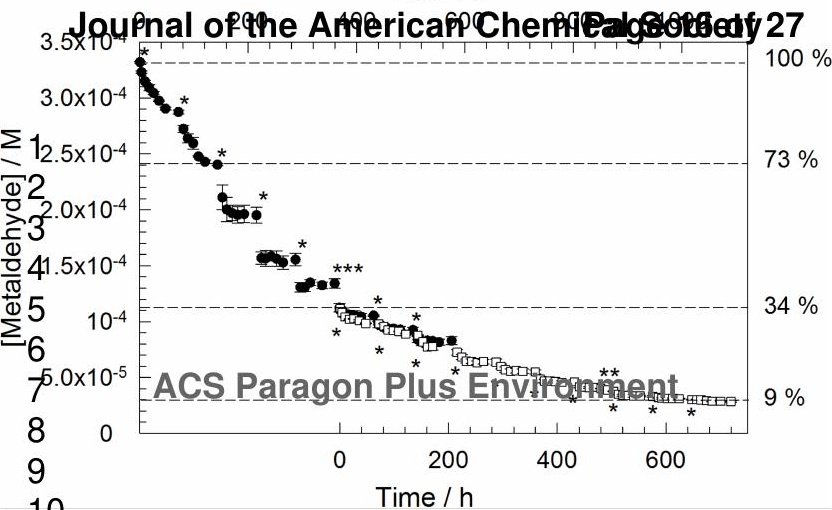




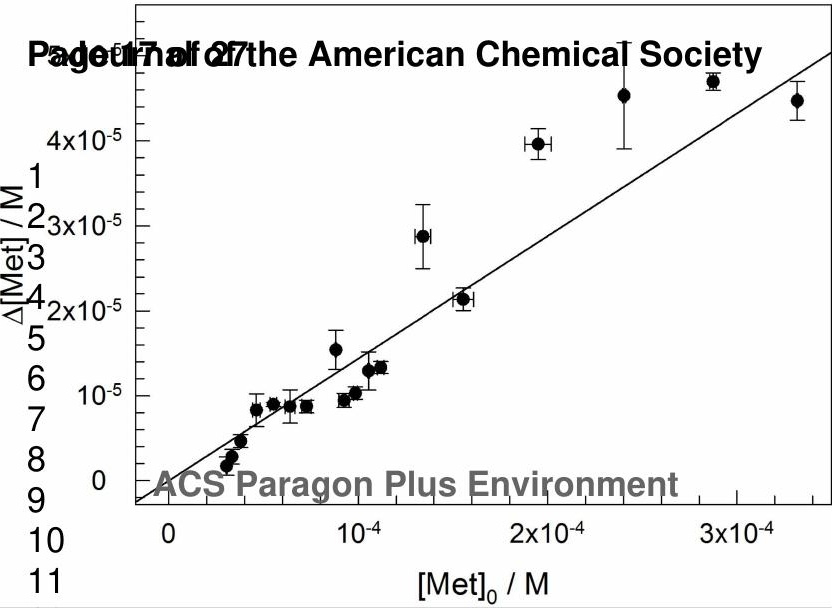


$\log \left(k_{\|} \times k_{\mathrm{i}}^{-1} / \mathrm{M}^{-1}\right)$ for any suitable catalyst $\begin{array}{lllllllllll}3 & 4 & 5 & 6 & 7 & 8 & 9 & 10 & 11 & 12 & 13\end{array}$

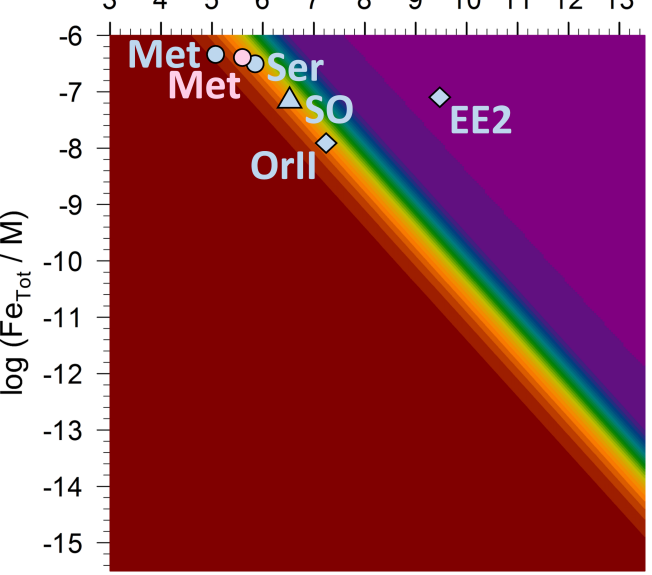

$\begin{array}{lllllllllll}0 & 1 & 2 & 3 & 4 & 5 & 6 & 7 & 8 & 9 & 10\end{array}$ $\mathrm{pH} 7, \log \left(k_{\|} / \mathrm{M}^{-1} \mathrm{~s}^{-1}\right)$ for $1 \mathrm{a} / \mathrm{NaClO} \mathrm{O}$ and $1 \mathrm{~b} / \mathrm{H}_{2} \mathrm{O}_{2} \diamond$

$\begin{array}{rrrrrrrrrrr} & & & & & & & & & & \\ 0 & 1 & 2 & 3 & 4 & 5 & 6 & 7 & 8 & 9 & 10\end{array}$ $\mathrm{pH} 7, \log \left(k_{\| 1} / \mathrm{M}^{-1} \mathrm{~s}^{-1}\right)$ for $1 \mathrm{a} / \mathrm{H}_{2} \mathrm{O}_{2} \mathrm{O}$

$\begin{array}{llllllllll}1 & 2 & 3 & 4 & 5 & 6 & 7 & 8 & 9 & 10\end{array}$ $\mathrm{pH} 11, \log \left(k_{\|} / \mathrm{M}^{-1} s^{-1}\right)$ for $\mathbf{1 b} / \mathrm{H}_{2} \mathrm{O}_{2} \triangle$ 


\section{Pageurinalf 87 the American Chemical Society}

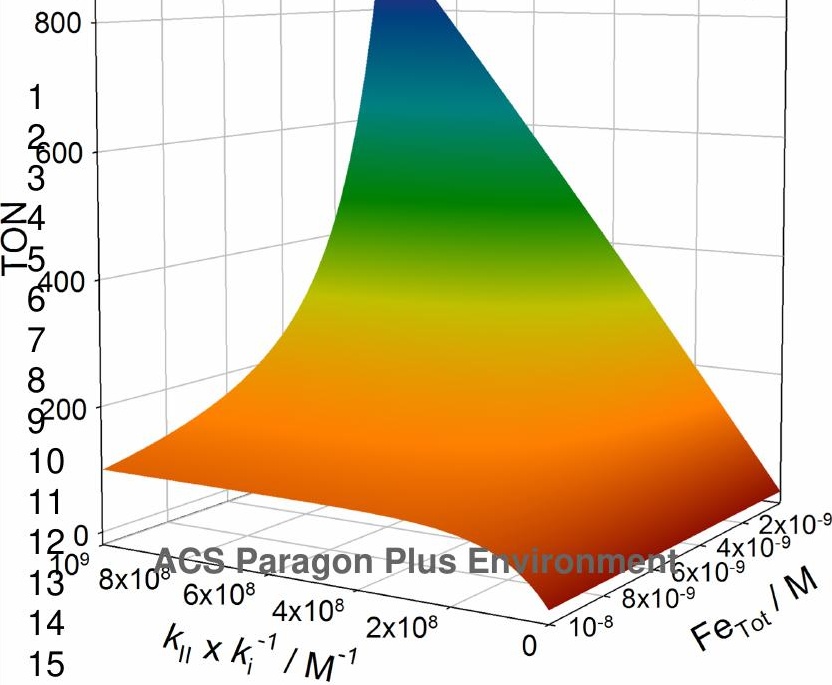




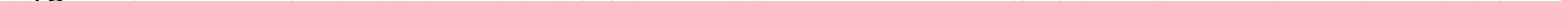




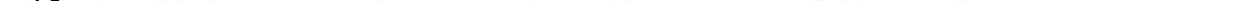




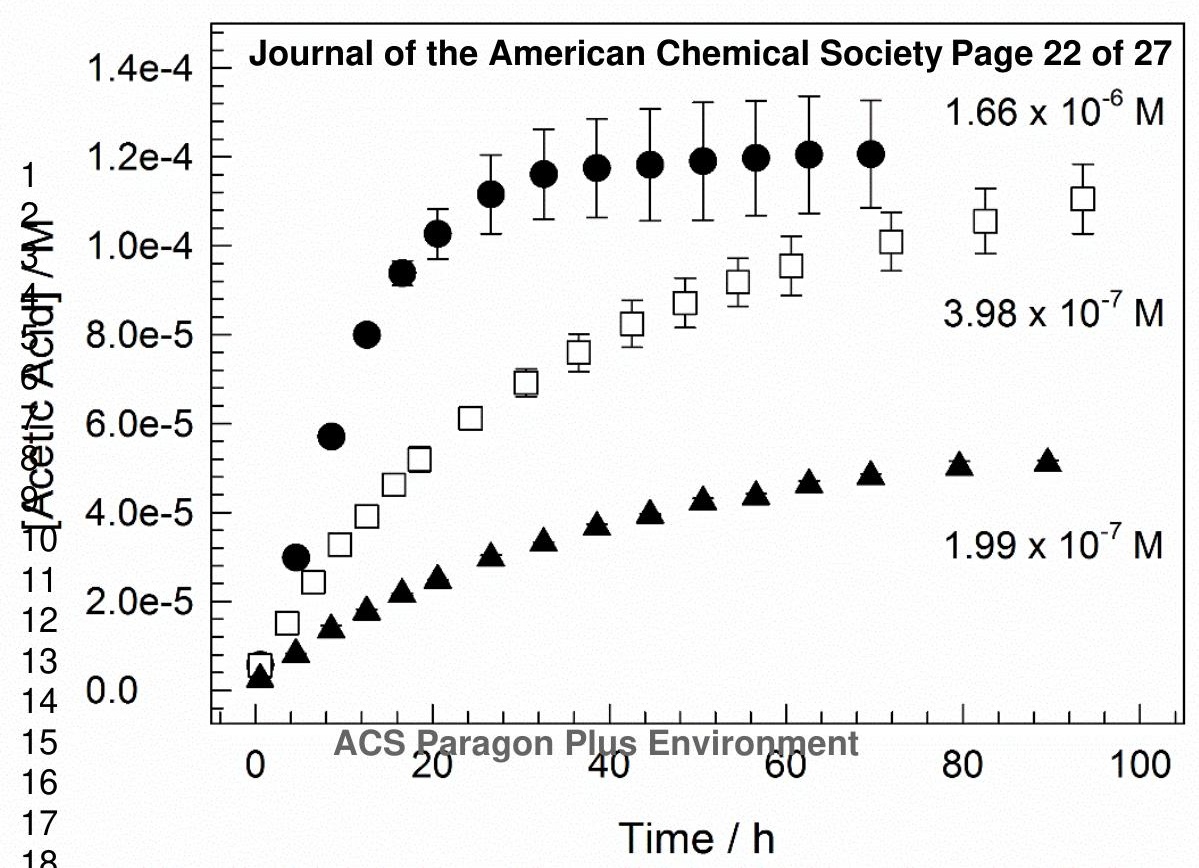




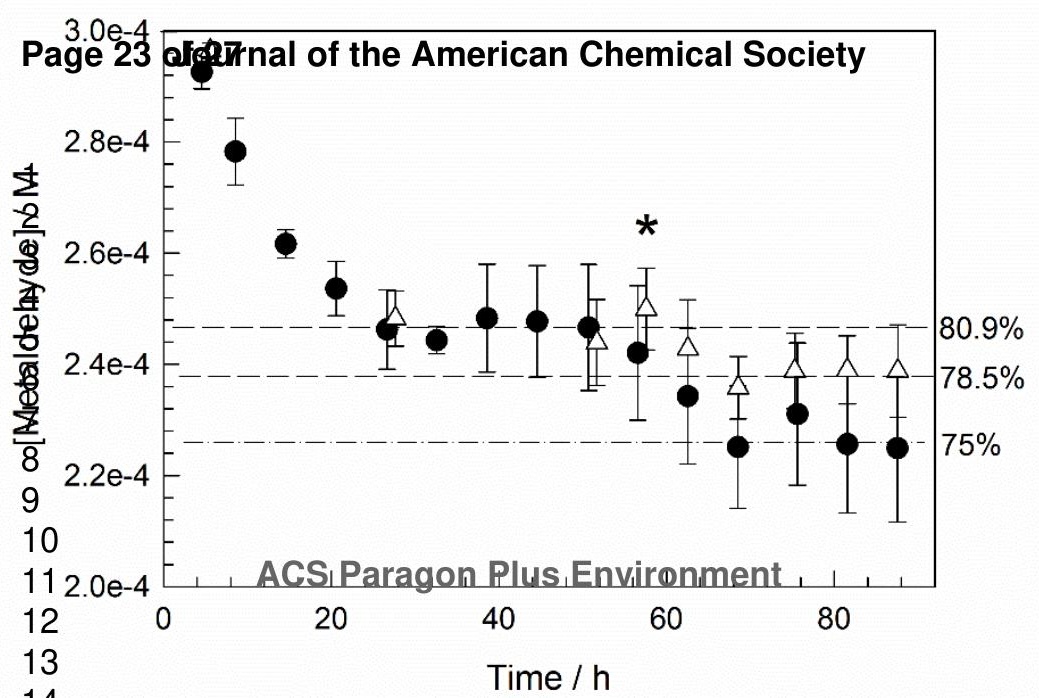




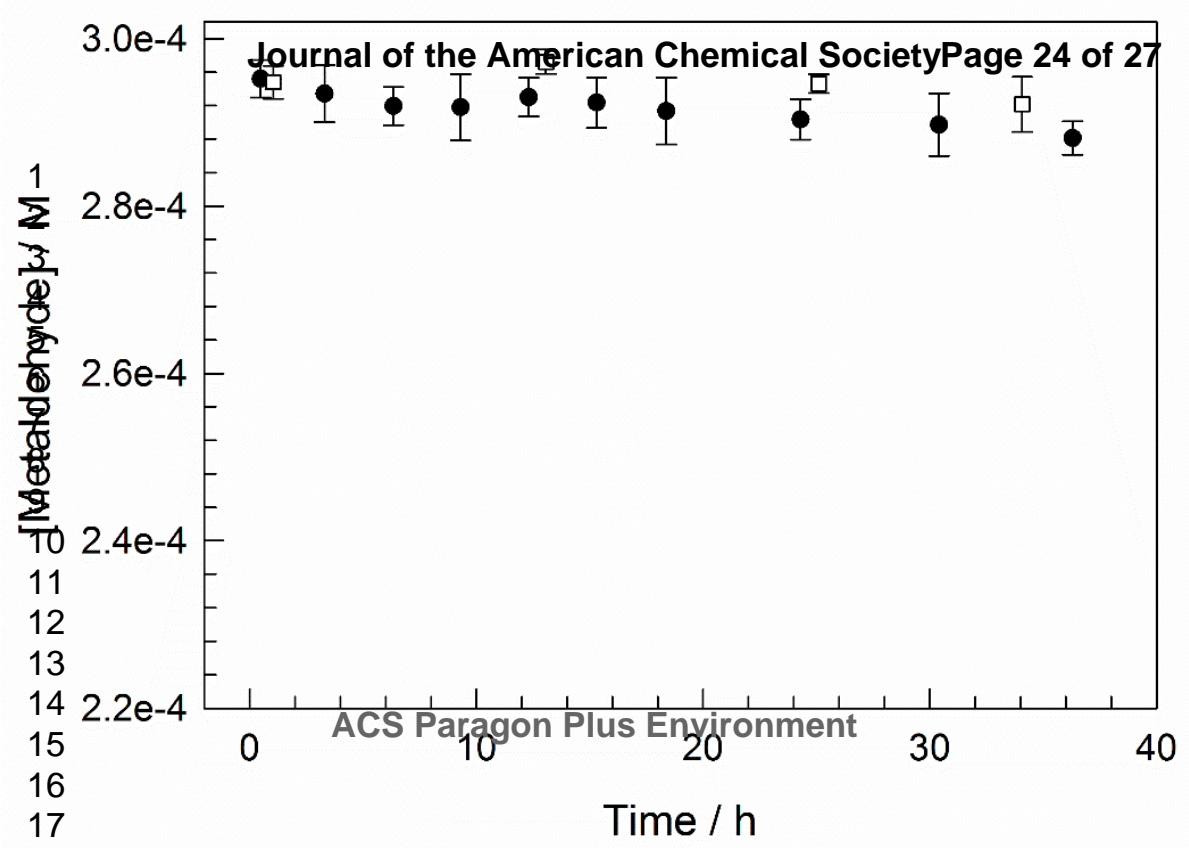




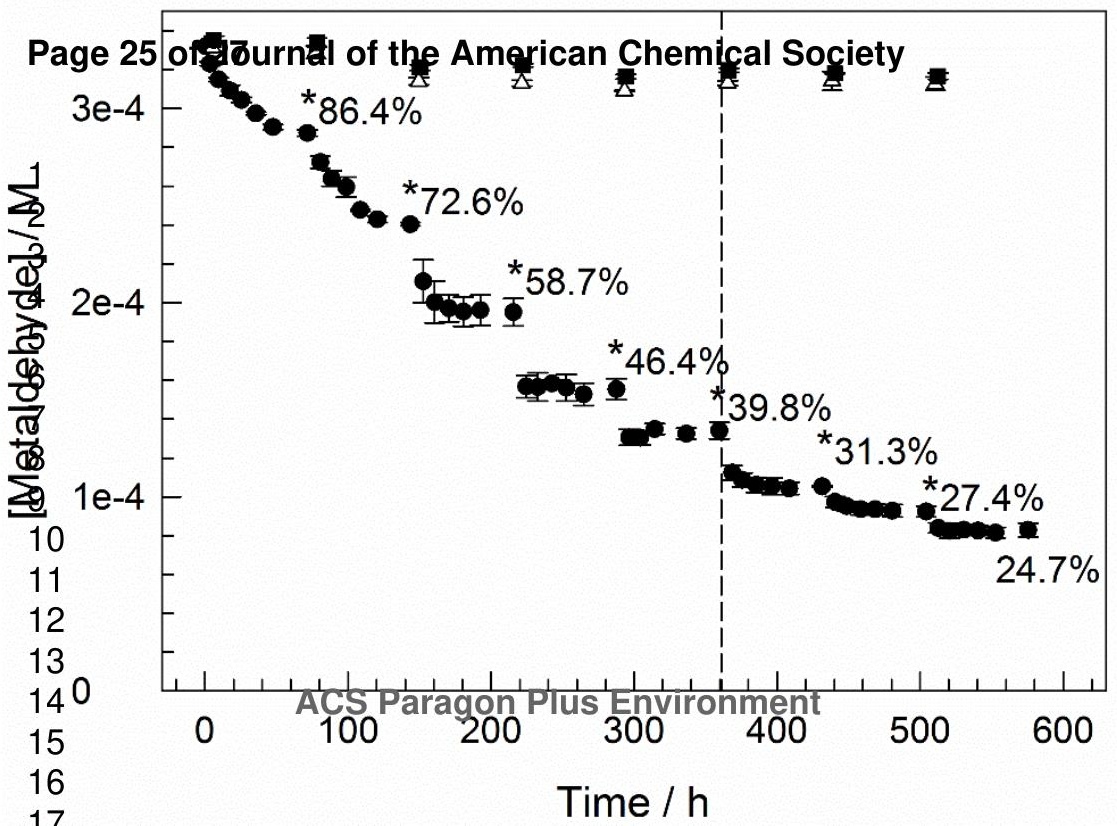


Journal of the American Chemical Sociefyage 26 of 27 6

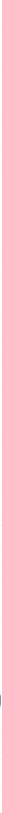


Page 27 of 27 Journal of the American Chemical Society

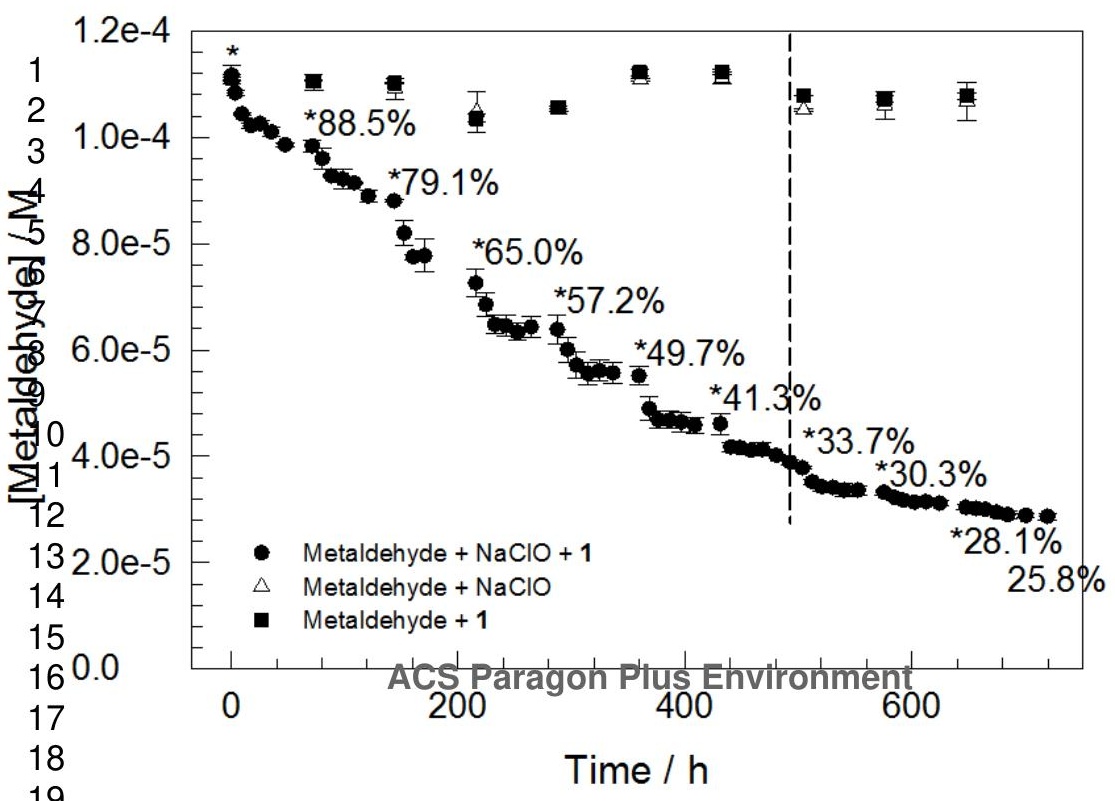

